\title{
PHYSICAL-BIOLOGICAL COUPLING ON OYSTER REEFS: HOW HABITAT STRUCTURE INFLUENCES INDIVIDUAL PERFORMANCE
}

\author{
HUNTER S. LENIHAN ${ }^{1}$ \\ Institute of Marine Sciences, University of North Carolina at Chapel Hill, 3431 Arendell Street, \\ Morehead City, North Carolina 28557 USA
}

\begin{abstract}
A large-scale field experiment was conducted to test whether the physical structure of biogenic reef habitat controls physical conditions (hydrodynamics and hydrographics) with subsequent influence on the performance (recruitment, growth, and survival) of a benthic suspension feeder. The experimental system consisted of restored subtidal oyster reefs inhabited by the eastern oyster Crassostrea virginica. To determine whether the size of reefs influences the flow environment and oyster performance, reefs of four heights - tall $(2 \mathrm{~m})$, short $(1 \mathrm{~m})$, dredged $(0.6 \mathrm{~m})$, and low $(0.1 \mathrm{~m})$-were constructed at 3-m water depth in the Neuse River estuary, North Carolina, USA. To test whether oyster performance varies with water depth and hydrographic conditions, tall and short reefs were also constructed at 6-m water depth. Flow speed, sedimentation, temperature, salinity, dissolved oxygen, and the performance of oysters were measured as a function of reef height, position on reef, and water depth over a 10-mo period. Flow speed was found to increase on reefs with reef height and elevation on reefs. Rates of sediment deposition were seasonally highest where flow speed was lowest, at the bases of reefs, and seasonally decreased with increasing water depth. More than $90 \%$ of the surface area of low reefs was buried after only 16 mo of exposure in the estuary, indicating that reef height controls habitat quality (and quantity) indirectly through its effect on flow. Short reefs and the bases of tall reefs at 6-m depth were exposed to a total of $26 \mathrm{~d}$ of hypoxia/anoxia. No other reef treatment was exposed to $>5 \mathrm{~d}$ of hypoxia.

Physical conditions on experimental reefs had a profound influence on the performance of oysters as the flow environment alone explained $81 \%$ of variability in oyster growth and mortality. Recruitment of oysters over a 2-mo period was slightly higher on the front bases than the crests of reefs, but did not vary with reef height or water depth. After 10 mo, the shell growth and condition index of genetically similar, hatchery-raised oysters were greatest on the crests of tall and short reefs, where flow speed and quality of suspended food material were highest, and sediment deposition was lowest. Growth was greatest overall at the crests of tall reefs located at 6-m water depth where flow speed was high, and the numbers of days exposed to hypoxia/anoxia and variation in salinity were lowest. Total percentage mortality of oysters after 10 mo was greater on low reefs located at 3-m depth than on all other reef types and was greater on the bases than crests of tall, short, and dredged reefs. Predation by crabs and fishes accounted for 4-20\% of total oyster mortality and showed no pattern across reef treatments. Results of this experiment indicate (1) that the physical structure and location of biogenic habitat controls local physical variables and (2) that, in turn, physical variables, especially flow speed, have a profound influence on the performance of a resident species. Realization that an ecological function of habitat is to indirectly control local population production through physical-biological coupling should improve our ability to conserve, restore, and manage habitat and associated species diversity. Better ecological engineering of restored oyster reef habitat is likely to improve fishery production and help maintain estuarine biodiversity.
\end{abstract}

Key words: Crassostrea virginica; estuary; flow speed; hydrodynamics; hydrographics; mortality; oyster growth; predation; recruitment; reefs; sedimentation; suspension feeders.

\section{INTRODUCTION}

Ecologists have long recognized that the physical structure of habitat influences population biology and species interactions (Bell et al. 1991). Physical habitat structure can directly control the distribution and abun-

Manuscript received 27 April 1998; revised 31 August 1998; accepted 29 September 1998.

${ }^{1}$ E-mail: hsleniha@email.unc.edu dance of associated species by providing necessary resources, including substrate for colonization (Underwood and Denley 1984), and refuges from competition (MacArthur and MacArthur 1961), predation (Huffaker 1958), and disturbance (Dayton 1971). In addition, physical habitat structure can indirectly influence local species through physical-biological coupling, that is, by altering physical variables which have subsequent biological effects (Belsky et al. 1989, Mann and Lazier 
1991). For example, in the terrestrial environment, trees modify the local wind current thereby altering patterns of seed dispersal and deposition (Murray 1986). The ecological consequence of physical-biological coupling is well appreciated in the marine environment, where attention to how habitats influence flow regimes (Vogel 1981), salinity (Kinne 1963), temperature (Kinne 1963), and dissolved oxygen concentration (Diaz and Rosenberg 1995) are part of the tradition of marine ecological research. Missing from marine (and terrestrial) research are experiments that quantify what proportion of the variation in an organism's performance (e.g., recruitment, growth, reproduction, and survival) is explained by physical-biological coupling. Quantifying the effect of physicalbiological coupling on an organism's performance will allow us to create predictive models useful to habitat conservation and restoration. The most crucial question, therefore, is not whether habitat structure or physical variables alone affect an individual's performance, but rather, how much of performance is influenced by habitat structure through the modification of physical variables.

In this paper, I report the results of a large-scale experiment designed to manipulate the physical structure of biogenic oyster reef habitat to assess (1) how reefs control local physical variables and (2) how these variables, in turn, influence the performance of oysters. Reefs created by the eastern oyster Crassostrea virginica were used as the experimental system because their size, shape, and location control exposure to local environmental conditions with subsequent effects on resident organisms (Wells 1961, Seliger et al. 1985, Breitburg 1992, Lenihan and Peterson 1998). Oysters and oyster reefs also have important economical and ecological relevance. The eastern oyster supports a multimillion dollar fishing industry in the United States (MacKenzie 1996). Oysters filter large volumes of estuarine water thereby potentially affecting phytoplankton dynamics and water quality (Newell 1988). Oyster reefs also maintain estuarine biodiversity and fisheries production by providing colonization space, refuge, and foraging substrate for many invertebrates and fishes (Arve 1960, Bahr and Lanier 1981, Zimmerman et al. 1989, Lenihan et al. 1998).

The physical variables I focused on, flow speed and hydrographics, have major impacts on the individual performance and production of aquatic organisms. The alteration of flow speed by marine benthic habitat influences rates of larval settlement (Breitburg et al. 1995), recruitment (Eckman 1983), feeding (Muschenheim 1987, Butman et al. 1994, Sanford et al. 1994), growth (Genin et al. 1986, Irlandi and Peterson 1991, Leichter and Witman 1997), predation (Skilleter and Peterson 1994), and community composition (Wildish and Kristmanson 1979, Baynes and Szmant 1989, Leonard et al. 1998) of benthic organisms. Hydrodynamic conditions on oyster reefs should control the delivery rate and retention of planktonic oyster larvae, suspended food material to suspension-feeding oysters, and sediment, thereby influencing the recruitment, growth, and survival of oysters, and the quality of oyster reef habitat. The physical structure and location of marine benthic habitat also influence resident populations by controlling exposure to hydrographic conditions (Wishner et al. 1990, Witman et al. 1993). In estuaries, which are often subject to strong horizontal and vertical gradients in hydrographic conditions, the location and size (e.g., height) of oyster reefs should control variation in salinity, temperature, dissolved oxygen concentration (Seliger et al. 1985, Breitburg 1992), and food availability (Anders and Lopez 1988), and, therefore, the subsequent production of oysters.

Realization that marine biogenic habitats function ecologically to sustain species diversity and fishery production has led to the preservation and restoration of salt marshes, seagrasses, and coral reefs (Kelleher and Kenchington 1992). The same protection has not been extended to oyster reefs, which are heavily disturbed and degraded by destructive fishing practices (Rothschild et al. 1994, Lenihan and Peterson 1998). At present, a great deal of money is spent to restore oyster reef habitat to maintain oyster harvests without much success (Hargis and Haven 1988, Frankenberg 1995). A better understanding of how physical habitat structure influences the production of a resident species is likely to improve our ability to manage and restore such exploited habitats through better ecological engineering (Jones et al. 1994). Thayer (1992) suggests that to successfully restore habitat, we must recognize and recreate its functional properties, and that, at present, we know relatively little about how habitats function ecologically, especially in the marine environment. To determine how physical habitat structure influences a resident species indirectly through physical-biological coupling, I tested the general hypothesis that the size and location of oyster reefs control the local flow environment and hydrographics, which, in turn, influence oyster recruitment, growth, and survival.

\section{Hypotheses and predictions}

I tested seven specific hypotheses to address my general question. Based on the principle of continuity (see Fig. 1), I reasoned that oyster reefs not only project above the boundary layer into regions of the water column where flow speed naturally increases with elevation, but that reefs alter local hydrodynamics, which have subsequent effects on sedimentation processes and oyster performance. Therefore, I hypothesized that (1) flow speed over reefs is greater than at similar elevations above the seafloor away from reefs; (2) flow increases with reef height and elevation on reefs; (3) sediment deposition and burial is highest on reefs experiencing the lowest flow speed; and (4) oyster performance (recruitment, growth, physical condition, and survival) increases with flow speed but decreases with 

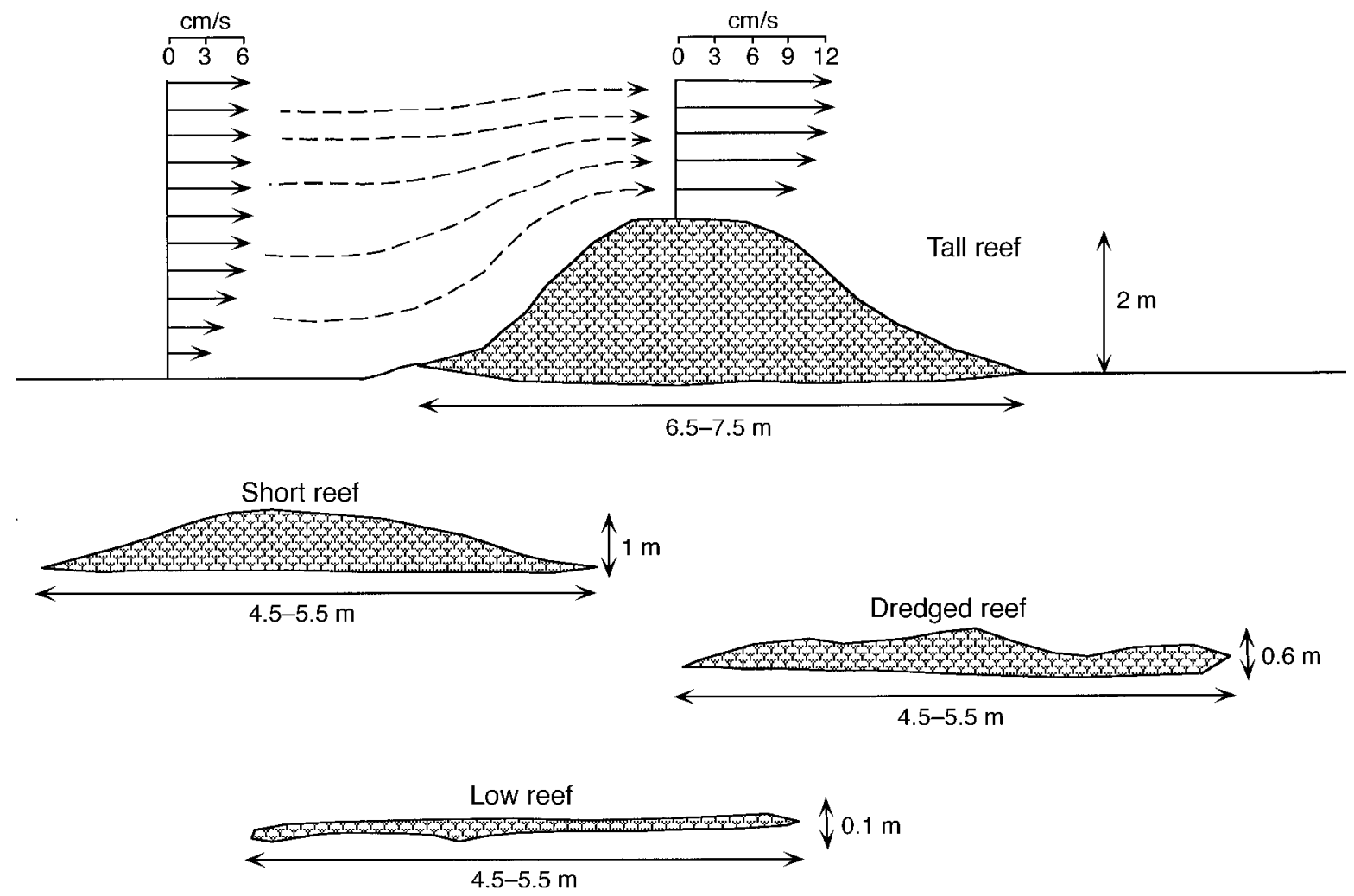

FIG. 1. Sizes and shapes of four types of experimental oyster reefs used in this study. Reefs were constructed with piles of oyster shells. Arrow diagrams above tall reef illustrate the behavior of flow predicted by the principle of continuity. The principle of continuity predicts that, as the height of an object on the seafloor increases, the volume of water above the object decreases, so to conserve mass, the velocity of water flowing over the object must increase.

sedimentation. I also tested whether (5) flow speed over reefs changes with water depth within a stratified estuary; (6) oyster recruitment increases with water depth because planktonic oyster larvae tend to accumulate in deep portions of estuaries experiencing net upstream flow (Galtsoff 1964); and (7) oyster performance decreases with water depth in an estuary because of increasing exposure to hypoxia/anoxia. Finally, I quantified the proportion of variation in oyster growth and mortality explained by hydrodynamic and hydrographic variables.

\section{Methods \\ Study organism}

The eastern oyster Crassostrea virginica inhabits estuarine and coastal waters from the Gulf of St. Lawrence, in Canada, to Argentina (Carriker and Gaffney 1996). Temperature, salinity, and their interaction are abiotic factors that profoundly influence the development, feeding, growth, reproduction, survival, and parasitic infection of oysters (Shumway 1996). Oysters live in water temperatures of $0^{\circ}-36^{\circ} \mathrm{C}$ and salinities of 0-40 practical salinity units (psu), but have the highest growth and reproductive rates, and lowest overall mortality, in temperatures ranging from $20^{\circ}-30^{\circ} \mathrm{C}$ and sa- linities ranging from 15 to 30 psu (Shumway 1996). Healthy adult oysters can withstand hypoxic conditions $\left(<2 \mathrm{mg} \mathrm{O}_{2} / \mathrm{L}\right)$ for $7-10 \mathrm{~d}$ in $18^{\circ} \mathrm{C}$ water, but can last several weeks without oxygen if water temperature is $<5^{\circ} \mathrm{C}$ (Jordan et al. 1992). Spawning and recruitment of oysters in North Carolina, USA, where this study was conducted, are greatest during August-October (Ortega and Sutherland 1990). Under controlled laboratory conditions, oyster growth increases with flow speed $(0-10 \mathrm{~cm} / \mathrm{s})$ and food concentration (Lenihan et al. 1996). Oysters can survive and grow when exposed to relatively high sediment deposition in the laboratory (Ali 1981), but, like other bivalves, very high deposition rates reduce recruitment, slow growth, and increase mortality in the field (MacKenzie 1983, Grant et al. 1990). Common oyster predators in estuaries of the eastern United States include polyclad turbellarian flatworms, mud crabs (Panopeus herbstii, Eurypanopeus depressus), the blue crab (Callinectes sapidus), the stone crab (Menipes mercenaria), and fishes, including sheepshead (Archosargus probatocephalus) and toadfish (Opsanus tau) (White and Wilson 1996).

Oysters and oyster reef habitat have declined dramatically in major estuaries of the eastern United States over the past century due to habitat degradation (Roths- 


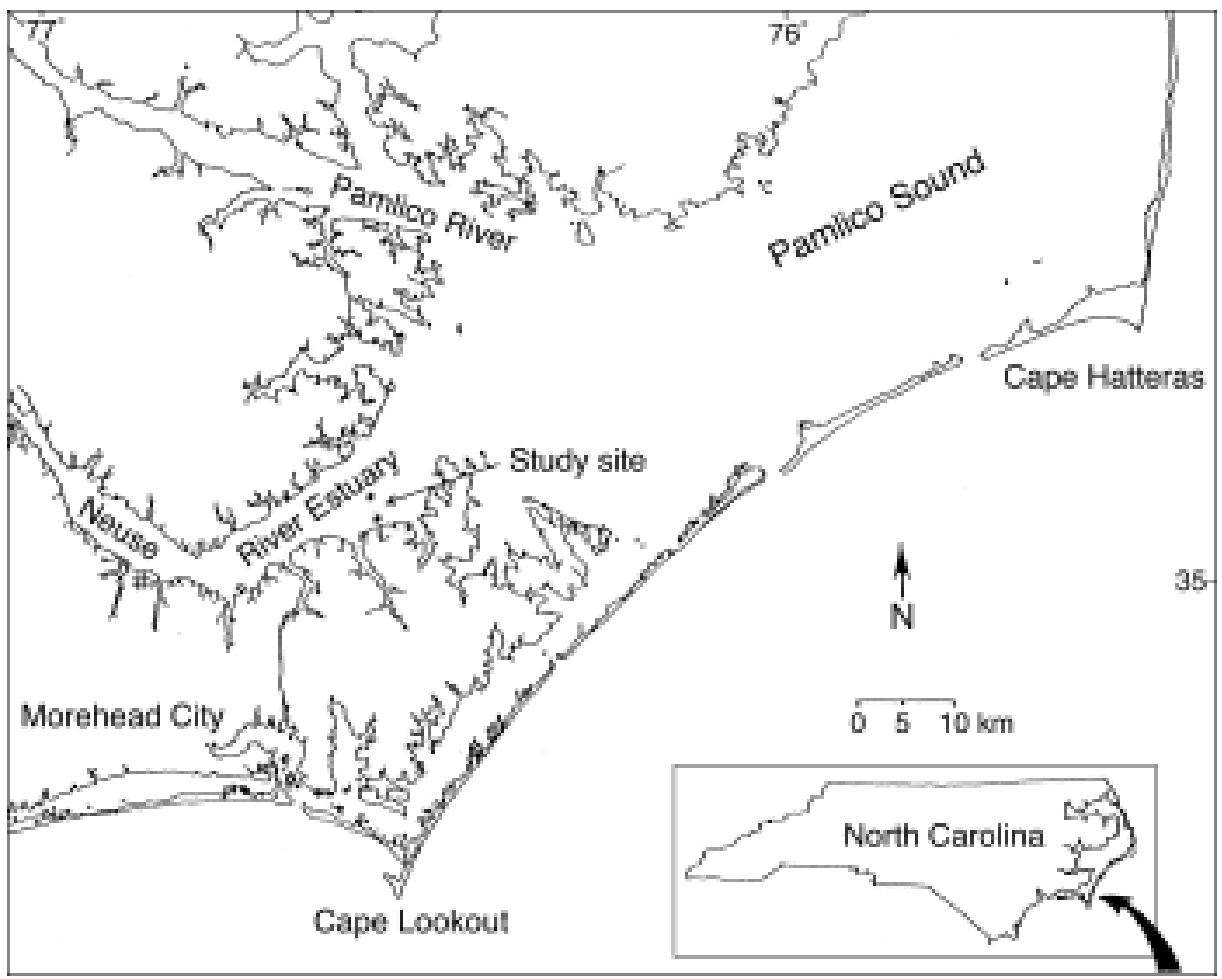

FIG. 2. Study site in the Neuse River estuary, North Carolina, USA. The location of experimentally restored oyster reefs is indicated by two asterisks $(*)$, with each asterisk representing a set of restored reefs at 3- or 6-m water depth (6-m reefs are farthest from the southern shore).

child et al. 1994), overfishing (Gross and Smyth 1946), reduced water quality (Seliger et al. 1985), the introduction of diseases (Ford and Tripp 1996, Lenihan et al., in press), and interactions among these factors (Lenihan and Peterson 1998). The substantial effort made by fishery and habitat managers to restore oyster reef habitat to maintain oyster and clam fisheries has been unsuccessful mainly because oysters do not reach harvest size ( $7 \mathrm{~cm}$ in height) before they die of disease, are buried beneath sediments, or are exposed to other stressful environmental conditions (Frankenberg 1995).

\section{Study site}

Experiments were conducted in the Neuse River estuary, North Carolina (Fig. 2), which is well described elsewhere (Wells and Kim 1989, Mallin and Paerl 1994). Production and harvests of oysters have been historically high in the Neuse River but have declined over the last 50 years due mainly to habitat destruction, reduced water quality, and disease (Lenihan and Peterson 1998, Lenihan et al., in press). This estuary is a typical mesohaline habitat for Crassostrea, with salinity ranging from 5 to 30 psu and water temperature $0^{\circ}-32^{\circ} \mathrm{C}$ (Paerl et al. 1995). The estuary is $\sim 50 \mathrm{~km}$ in length, 7-10 km in width, and has a central channel that is $4-7 \mathrm{~m}$ in water depth. The lunar tidal range is $\sim 20 \mathrm{~cm}$, but changes in sea level, currents, and cir- culation are due predominantly to winds and freshwater runoff (Pietrafessa et al. 1986). Wind direction is usually from the northeast in winter and southwest in other seasons (Wells and Kim 1989). Wind velocity and direction, runoff, and air temperature are also the major factors that control vertical and horizontal gradients of water temperature, salinity, and dissolved oxygen concentration (Paerl et al. 1995). The estuarine bottom is composed primarily of silt and clay, except for shallow margins, which are mostly sand (Wells and Kim 1989). The Neuse River estuary contains over 50 large, natural subtidal oyster reefs (each $0.20-2$ ha in surface area) occurring in water depths from 3 to $6.5 \mathrm{~m}$ (Lenihan and Peterson 1998). The North Carolina Division of Marine Fisheries (NCDMF) has restored oyster reef habitat in the estuary since 1978 by creating piles of dead Crassostrea shells in several locations. Although other materials are used to restore reefs (e.g., scallop and clam shells), oyster shells are used most often because oysters are gregarious settlers chemically attracted by proteins emitted from oyster shells (Turner et al. 1994). The Neuse River estuary is subject to periodic, prolonged periods of hypoxia/anoxia caused by vertical stratification, atmospheric forcing (i.e., a lack of wind mixing of the water column), and anthropogenic eutrophication (Paerl et al. 1995). Mass mortality of oysters, reef associated invertebrates, and fishes occurs during hypoxia/anoxic events (Lenihan and Peterson 


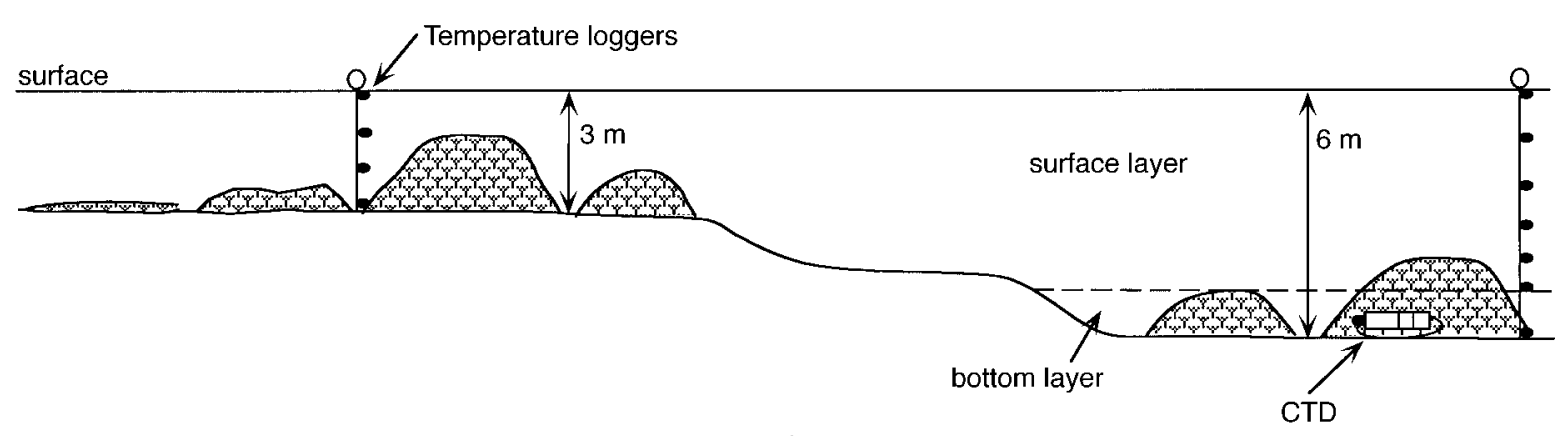

$1.5 \mathrm{~km}$

FIG. 3. Experimental design of study showing placement of restored oyster reefs in the Neuse River estuary. Tall, short, dredged, and low reefs $(N=12$ of each reef type) were located at $3-\mathrm{m}$ water depth, and 12 tall and 12 short reefs were located at 6-m depth. Horizontal scale of river width is grossly compressed, and slightly decreased for experimental reefs. Actual distance between reefs was 10-32 m. Actual heights and diameters of reefs are given in Fig. 1. CTD is a conductivitytemperature-depth measuring device (see Methods: Hydrographic Conditions).

1998). Bottom water hypoxia/anoxia usually occurs in the estuary during periods of vertical stratification, especially following freshwater runoff events in summer.

\section{Experimental oyster reefs}

To test my hypotheses, 12 replicate oyster shell reefs of each of four heights, tall (2 m tall, roughly hemispherical in shape), short (1 $\mathrm{m}$ tall, hemispherical), dredged $(0.6 \mathrm{~m}$ tall, $1 \mathrm{~m}$ tall reefs that were reduced in height by physically disturbing them with oyster dredges), and low (0.1 $\mathrm{m}$ tall, roughly circular), were constructed at 3-m water depth in the Neuse River estuary (Figs. 1 and 2). Tall reefs were $6.5-7.5 \mathrm{~m}$ in diameter and $33-38 \mathrm{~m}^{2}$ in area, and were used to mimic $2 \mathrm{~m}$ tall natural oyster reefs that existed in the Neuse prior to the advent of dredge harvesting. Short reefs were $4.5-5.5 \mathrm{~m}$ in diameter and $16-20 \mathrm{~m}^{2}$ in area, and were used to mimic the most common type of restored oyster reef constructed by the NCDMF in their oyster reef restoration program. Dredged reefs were 4.5-5.5 $\mathrm{m}$ in diameter and $16-20 \mathrm{~m}^{2}$ in area, and were created by passing a $50-\mathrm{kg}$ oyster dredge over small reefs $9-$ 10 times. Oyster dredging of small reefs was executed in order to approximate the physical disturbance and reduction in reef height caused by oyster dredging (e.g., Lenihan and Peterson 1998). Low reefs were also 4.5$5.5 \mathrm{~m}$ in diameter and $16-20 \mathrm{~m}^{2}$ in area. Low reefs were used to mimic another common reef type produced in North Carolina's oyster reef restoration program.

To test whether location of reefs (i.e., water depth) and hydrographic conditions influence oyster performance, an additional set of 12 tall and 12 short reefs were built at 6-m water depth (Fig. 3). The nearest distance between replicate reefs at all water depths ranged from 18 to $32 \mathrm{~m}$. Reefs were built in July 1993 with help from the NCDMF using methods employed in their oyster reef restoration program: by dumping oyster shell from a remodeled 35-m long U.S. Navy LCU-1466 landing craft using a bulldozer. The height of each reef was measured during construction by divers using a plumb line attached to a buoy, and shell was added or removed manually by divers as needed to obtain desired dimensions. Construction of the 72 reefs required a total of $\sim 6000 \mathrm{~m}^{3}$ of oyster shells. The experimental site was designated as a research sanctuary and potentially destructive oyster dredging and shrimp trawling activities were prevented by placing large buoys around the perimeter of the site.

After reef construction, flow speed across reefs, sedimentation on and burial of reefs, and oyster recruitment, growth, condition, and survival were measured as a function of water depth, reef height, and position on reefs. For 10 mo, beginning in August 1994, temperature, salinity, and dissolved oxygen concentration were measured frequently around reefs as a function of water depth and elevation above the estuarine seafloor.

\section{Physical conditions influenced by reef size and location}

Flow speed.-Flow speed over reefs was measured to determine whether the height of oyster reefs controls the hydrodynamic environment of oysters. Like many other suspension-feeding bivalves, growth, condition, and survival of oysters respond positively to increased flow (Lenihan et al. 1996). Flow can also control the sedimentary environment which, in turn, has subsequent influence on the growth and survival of benthic suspension-feeding organisms (Muschenheim 1987), including oysters (Ali 1981). Three hypotheses about the flow environment on reefs were tested: (1) that reefs alter flow and do not just project oysters above the benthic boundary into the water column where flow naturally increases with elevation; (2) that flow increases with reef height and elevation on reefs at 3-m depth, thereby explaining variation in oyster performance on the four experimental reef types; and (3) that flow over reefs varies with water depth in a stratified 


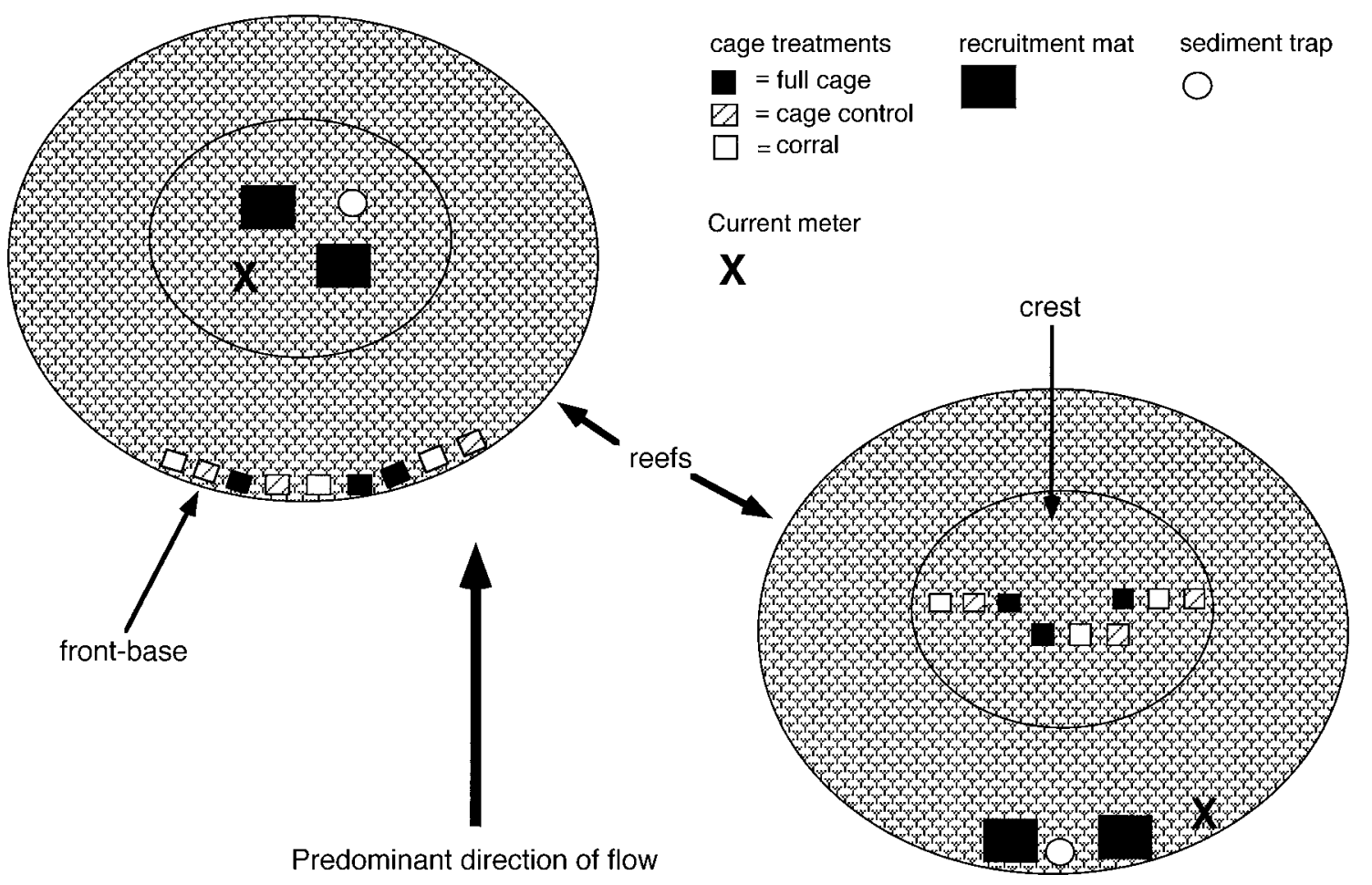

FIG. 4. The exact number and relative locations of sampling devices (current meters, sediment traps, recruitment mats, and cages for oysters) placed on the front bases and crests of experimental oyster reefs during the experiment. Recruitment mats were always placed on reefs in pairs, and cage treatments (full cages, cage controls, and corrals) were always placed in sets of three (as shown). Devices on the front bases of reefs were situated near the seafloor-reef interface, and at $0.1 \mathrm{~m}$ (low reefs), $0.6 \mathrm{~m}$ (dredged), $1.0 \mathrm{~m}$ (short), or $2.0 \mathrm{~m}$ (tall) elevation on the crests of reefs.

estuary, thereby explaining variation in oyster performance observed across depth.

Current measurements were made on experimental reefs with InterOcean S-4 current meters (Interocean, San Diego, California, USA). The current meters were placed at various positions on reefs, with the two most common positions being the crest and the front base of reefs where sedimentation and oyster performance were also measured (Fig. 4). The front base of reefs refers to the bottom of reefs on the side that faced into the direction of oncoming flow most often during (1) long-term measurements of flow and (2) hundreds of visual observations made under a variety of environmental conditions (H. S. Lenihan, personal observation). The front base of reefs at 3-m water depth was the side of reefs facing upstream, and was the side facing downstream at 6-m depth. To test the first hypothesis that oyster reefs significantly affect ambient flow, current speed was measured on each of two replicate tall and short reefs located at 6-m water depth, and at similar vertical distances above the seafloor away from reefs, also at 6-m depth, on 10 December 1994. Five positions on each of the tall reefs were selected, the crest ( $2.2 \mathrm{~m}$ above the seafloor), the sides of reefs normal to the direction of flow (at two locations; $1.2-\mathrm{m}$ and $30-\mathrm{cm}$ height), the front base of reefs (30-cm height), and the back base relative to flow (30- $\mathrm{cm}$ height). Four positions on each of the short reefs were selected, the crest (1.3-m height), the side normal to flow (30-cm height), the front base (30-cm height), and the back base relative to flow (30-cm height). Replicate current measurements taken at different positions on reefs were not made on the same reef in order to avoid problems of statistical nonindependence. Flow speed was also measured at similar heights above the seafloor at two separate locations away from reefs $(N$ $=2$ measurements for each elevation). Measurements taken away from reefs were made by anchoring a boat at two separate locations 200-m upstream from the experimental reefs, and suspending a current meter from a weighted winch cable. Current measurements in this test were made during "normal" flow conditions in the Neuse River estuary, when flow at 1-m elevation away from reefs at $3-\mathrm{m}$ depth was $6.1 \pm 1.1 \mathrm{~cm} / \mathrm{s}$. This qualitative description of flow condition is based on many short-term current measurements $(N=122)$ made at 1-m elevation at 3-m depth under a variety of wind conditions (Fig. 5A). To test the second hypothesis, that flow speed increases with reef height and elevation on reefs, flow was measured on the crest of each of three tall, short, dredged, and low reefs, and the front base of three other reefs of the same type $(N=$ three replicates per treatment) located at 3-m water depth. These measurements were made 12 and 29 March 1995. 
FIG. 5. Frequency diagram of flow speeds measured at (A) 1-m elevation above the seafloor away from reefs at 3-m water depth for short time periods, and (B) on the crests and front bases of tall and short reefs located at 3$\mathrm{m}$ depth over a 7-d and 34-d period. Measurements for (A) were taken repeatedly over the duration of the experiment. All values are average flow speeds measured over a $60-$ s period.

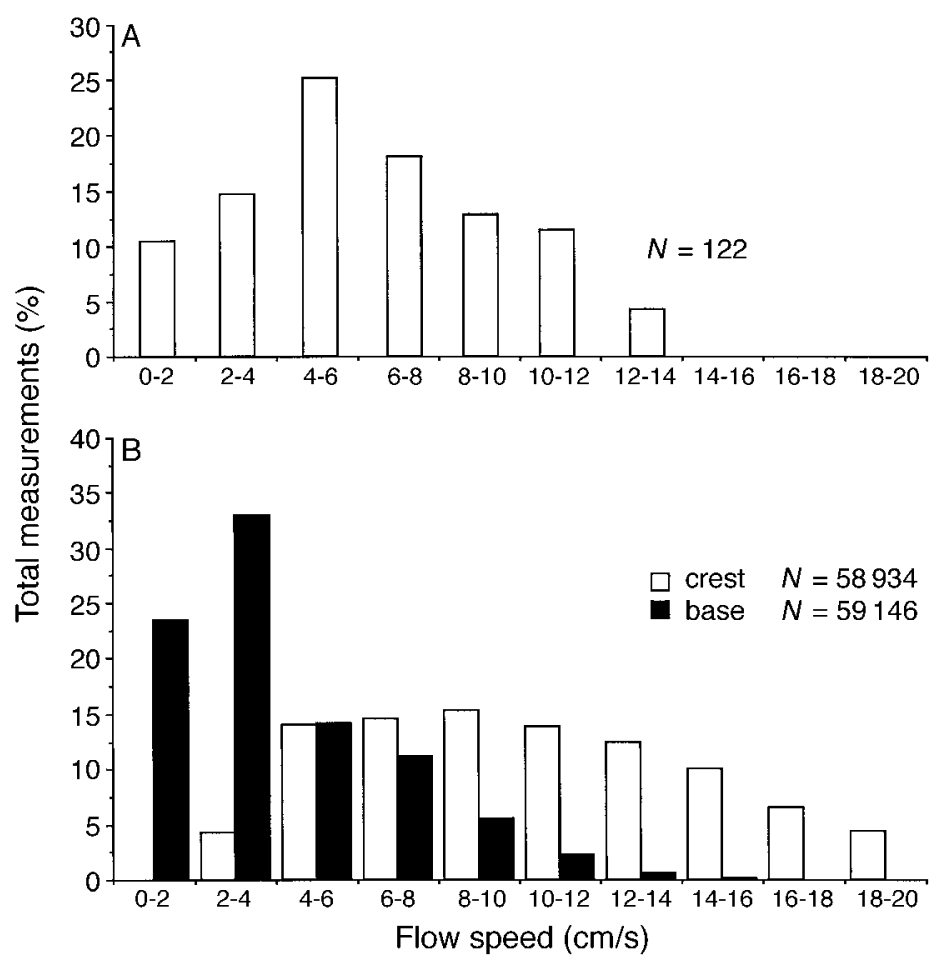

Current measurements in this test were made during normal (i.e., $5.9 \pm 0.9 \mathrm{~cm} / \mathrm{s}$ at $1-\mathrm{m}$ elevation away from reefs at $3-\mathrm{m}$ depth) and "fast" $(11.5 \pm 1.3 \mathrm{~cm} / \mathrm{s})$ flow conditions. To test the third hypothesis, that flow differs over reefs as a function of water depth, flow was measured on the crest and front base on replicate tall and short reefs at 3- and 6-m water depths. Measurements for this test were made on three replicate water depth $\times$ reef type $\times$ position on reef combinations, on 13 April 1995, during fast flow conditions (10.8 \pm 1.2 $\mathrm{cm} / \mathrm{s})$.

The current meters recorded 15 -s averages over sampling intervals of $15 \mathrm{~min}$ to $34 \mathrm{~d}$. To test the three main hypotheses concerning flow, a grand mean flow speed for each treatment replicate was calculated from 60 averages recorded over a 15-min sampling interval. Only two current meters were available for use in the field, so measurements taken across all treatments or treatment replicates were not made simultaneously. Instead, current meters were moved by divers among positions on reefs, or in the water column, until the desired number of measurements were taken. Temporal bias was possible among flow measurements made during any one test because only two current meters were used. Such temporal bias was minimized by (1) placing the two current meters simultaneously on a base and crest of reefs and (2) measuring currents only during relatively constant wind conditions. By placing current meters simultaneously on a base and crest, temporal variation in flow conditions among the experimental reefs would likely have been manifested as high within- treatment variance. Such high within-treatment variance was not observed (see Results). Furthermore, current measurements taken over periods from one week to one month, coupled with records of wind speed and direction, indicated that variation in flow through time and space at the experimental site were due overwhelmingly to the local wind field (H. S. Lenihan, personal observation). Short-term flow measurements reported herein were taken during constant wind conditions only. In addition to the short-term measurements, over 118,000 additional measurements were recorded on the front bases and crests of short and tall reefs at 3-m depth under a variety of wind conditions during sampling intervals of 7 and $34 \mathrm{~d}$. These data provide an estimate of the "population" of flow speeds measured over reefs (Fig. 5B). During all current measurements, current meters were mounted on $10 \mathrm{~cm}$ tall PVC plastic collars fitted on custom-built steel tripods, so the height at which currents were measured was always $30 \mathrm{~cm}$ above the substrate. The PVC collars prevented potential interference to the meter's electromagnetic sensors caused by the steel tripod and natural substrate (McNinch 1997).

Sediment deposition.-Sediment deposition was measured as a function of season (winter, spring, summer, and fall), water depth, reef height, and position on reef to determine its influence on reef habitat quality and the performance of oysters. Sedimentation rate was estimated by placing one cylindrical PVC plastic sediment trap $(10.1-\mathrm{cm}$ inside diameter $\times 25 \mathrm{~cm}$ deep; $0.008-\mathrm{m}^{2}$ surface area; e.g., McNinch 1997) on the front 
base or crest of reefs of each height located at 3- and 6-m water depths. Three reefs of each height at 3- and 6- $m$ depths received one trap on the front base, and three other reefs received one trap on the crest. All traps were set flush with the substrate. Traps were deployed for 6-wk periods during summer 1994 (10 August-24 September), fall 1994 (1 November-15 December), winter 1994-1995 (22 December-16 February), and spring 1995 (2 May-18 June) by divers, who capped tubes under water when collecting them. Different reefs at each water depth were used for sedimentation sampling every season. Samples were placed on ice in the field and frozen at $-20^{\circ} \mathrm{C}$ upon their return to the laboratory. Total sediment mass was determined by drying samples for $24 \mathrm{~h}$ at $60^{\circ} \mathrm{C}$, and weighing contents to the nearest $0.01 \mathrm{~g}$. Deposition is reported as mean $\mathrm{g} / \mathrm{m}^{2}$ over the 6 -wk period for each season.

Reef burial.-Burial of reefs beneath sediment was measured to help determine what type of restored oyster reef is the most likely to sustain oyster production over the long term. To test whether time, water depth, and reef height control the rate of reef burial, the percentage of reef surface completely buried beneath sediment was estimated on all reef types located at all water depths. Measurements were made on all 12 replicates of each reef type immediately and 3, 9, and 16 mo after reefs were constructed. Percentage burial measurements were made visually by divers, who divided reefs into 10 approximately even sections using lines attached to permanent steel rebar stakes, and estimated the percentage of area $(0,25,50,75$, or $100 \%)$ within each of the 10 sections completely covered by sediment. Reef substrate that was quantified as buried never reemerged from beneath sediments during the course of this study.

Hydrographic conditions. - The influence of hydrographic conditions on the performance of oysters was determined by measuring water temperature $(T)$, salinity $(S)$, and dissolved oxygen concentration (DO) around experimental oyster reefs located at 3- and 6-m water depths between 1 August 1994 and 2 July 1995. Vertical $T$ profiles were collected at both water depths during seven $30-\mathrm{d}$ periods using a string of HoboTemp temperature loggers (OnSet Computers, Pocasset, Massachusetts), which sampled every $24 \mathrm{~min}$ at the surface of the water and at positions in the water column that corresponded to depths where oysters were situated on experimental reefs. For example, if the water column was 3-m deep, $T$ was taken at the surface and at $1-\mathrm{m}$ (i.e., crests of tall reefs), 2-m (i.e., crests of short reefs), and 3-m (i.e., bases of reefs) water depths. Each string of temperature loggers was suspended between a buoy at the surface and an anchor on the seafloor. $S$, DO, and additional temperature measurements were measured at $5.5-\mathrm{m}$ water depth at the front base of a tall reef at 6-m depth during the seven $30-\mathrm{d}$ periods using a moored Sea-Bird SeaCat 16-DO CTD (a device that measures and records water conductivity [i.e., salinity], temperature, and depth; Seabird Oceanographic Instruments, Bellingham, Washington) with attached oxygen meter. The CTD sampled every $10 \mathrm{~min}$. A profiling Hydrolab H-20 CTD (Hydrolab Company, Austin, Texas) with attached oxygen meter was deployed from a boat frequently (ranging from every day to once every $2 \mathrm{wk}$, depending on conditions) throughout the duration of the experiment to provide $S$ and DO measurements at the surface and at water depths where oysters were located. The Hydrolab H-20 CTD sampled once every $5 \mathrm{~s}$. All water quality monitoring equipment was calibrated in the laboratory before and after deployment in order to correct for drift in measurements. A range and a mean $( \pm 1 \mathrm{SD})$ of each hydrographic variable are provided. Means were calculated by (1) averaging all measurements taken once a day, or (2) in the case of the long-term CTD deployments, when many samples were recorded daily, by calculating daily means of measurements taken over a $24-\mathrm{h}$ period, and then calculating a grand mean of the daily means.

Quality of suspended food particles. - To estimate the nutritional quality of suspended food material in water surrounding experimental reefs, water samples were collected several centimeters above the front base and crest of the reefs $(N=2$ tall and short reefs at 3and 6-m depths, and low reefs at 3-m depth) in 1-L plastic jars by divers on 1 July 1994 and 4 December 1995. Difference in nutritional quality of the suspended material was estimated by comparing the ratio particulate organic matter (POM) to particulate inorganic matter (PIM) of water samples. POM and PIM were measured by combusting filtrates at $350^{\circ} \mathrm{C}$ for $12 \mathrm{~h}$, and comparing post- and pre-combusted masses.

\section{Responses of oysters to physical conditions on reefs}

Recruitment.-Recruitment of oysters was compared across experimental reefs at 3-m depth as a function of reef height and position on reef (factors that control flow and particle deposition). In a second test, the influence of water depth (a factor that can control hydrographics and, potentially, the abundance of oyster larvae in stratified estuaries) on recruitment was also tested by measuring recruitment on reefs at 6-m depth. Recruitment was predicted to increase with reef height and elevation on reefs because the delivery rate of larvae was expected to increase with flow speed and the survival rate of early post-settlement oysters was expected to increase with decreasing sedimentation and burial. Hence, recruitment was predicted to be higher on the crest than the front base of reefs. In addition, recruitment was expected to be highest at the deeper station $(6 \mathrm{~m})$ because oyster larvae favor the upstream currents in deep portions of riverine estuaries to avoid being flushed into the ocean (Galtsoff 1964). Recruitment was measured on $0.16-\mathrm{m}^{2}$ squares of plastic 1.3 cm Vexar mesh (Reddon Net Company, Vancouver, British Columbia, Canada), upon which 10 large oyster shells (65-75 $\mathrm{mm}$ in height) were attached using small, 
plastic cable ties. Only oysters attached to the 10 shells were counted as recruits. Recruitment mats were secured on reefs using steel garden staples on 10-13 August 1994 and collected 16-18 October 1994 in order to integrate across a 2-mo period of highest oyster settlement (Ortega and Sutherland 1990). Consequently, oysters considered recruits in this study were up to 2-mo old. Half of the reefs (six) in each water depth $X$ reef type combination received two recruitment mats at the front bases, and half at the crests. Recruitment mats were collected by divers, placed aboard a boat, and returned to the laboratory where only live oysters were counted as recruits. For all descriptions and statistical comparisons of recruitment among treatments, a grand mean of recruits was calculated by pooling data from the two recruitment mats placed at each reef type $\times$ position on reef combination. Data from the two mats on each reef were pooled because variation in recruitment within positions on reefs was not relevant to the hypotheses being tested.

Growth, condition, and survival.-To test the influence of flow speed, sedimentation, and hydrographic conditions on oyster growth, condition, survival, and predation, genetically similar, hatchery-raised oysters were placed in enclosure cages, cage controls, or corrals on experimental reefs for a 10 -mo period. Full cages $(20 \mathrm{~cm}$ long $\times 20 \mathrm{~cm}$ wide $\times 20 \mathrm{~cm}$ tall), cage controls (cages without tops), and corrals (20 cm long $\times 20 \mathrm{~cm}$ wide $\times 2 \mathrm{~cm}$ tall, without tops and buried within the shell matrix of the reefs) were made of 1.3$\mathrm{cm}$ plastic mesh, and were attached to rebar frames. Enclosure cages were used to test the effect of predation on total mortality, and excluded the most common large predators of oysters found in mesohaline portions of estuaries of the eastern United States, primarily blue crabs and fishes (e.g., oyster toadfish and sheepshead). Blue crab recruits were removed immediately upon detection. Cages did not exclude small predators of oysters, such as flatworms and mud crabs. Cage controls were used to control for cage artifacts. The main artifact of cages was probably alteration of fine-scale hydrodynamics and cage controls very likely mimicked this artifact. Corrals were used to determine the predation rates on oysters in a more natural environment. The corrals prevented oysters from being washed into the shell matrix of the reefs and were designed to minimize the potential hydrodynamic artifacts caused by cages (i.e., they did not have sides projecting above the bottom; e.g., see Dayton and Oliver 1980). Three large, adult oyster shells (65-75 mm in height) were placed within each cage treatment to mimic natural habitat heterogeneity and small-scale flow conditions. Ten oysters (23.5-24.4 mm in height; 4320 oysters total) were placed in each replicate cage treatment on 17 August 1994; they were collected after 10 mo on 15 June 1995. Hatchery-raised oysters were purchased from ARC, Incorporated, Atlantic, North Carolina, USA.
Each of three reefs of each type at 3- and 6-m depths received three cages, cage controls, and corrals at the front base (Fig. 4). Three other reefs in each reef type $\times$ water depth combination received three sets of each cage treatment at the crest. A set of three cages of each type was used instead of one large cage to minimize the impact of experimental intrusions. For example, if only one large cage of each type was used and a blue crab recruited into and subsequently killed oysters, the chances of losing one whole replicate of a particular cage treatment would have been relatively high. For all descriptions and statistical analyses of oyster growth, condition index, survival, and predation mortality, data from the three cages of each type on each reef were pooled to produce a total of three replicates $(N=3)$ of each cage treatment for each reef type $\times$ position on reef combination. Data were pooled because within-cage type variation on each reef was not relevant to the hypotheses being tested.

Growth of individual oysters was determined by calculating the difference in maximum shell height measured before and after the 10-mo experiment. Shell sizes were measured to $0.1 \mathrm{~mm}$ using vernier calipers. Condition index (tissue dry mass/[shell mass - total wet mass]) was used in addition to shell growth because shell size does not always provide the best measure of oyster growth; soft tissue of an oyster can decrease in size due to disease, starvation, and reproductive condition (Newell and Langdon 1996). Condition index also represents an estimate of physiological health. Condition index of oysters was recorded by measuring total mass of towel dried oysters, removing all somatic and gonadal tissue, drying soft tissue for $12 \mathrm{~h}$ at $60^{\circ} \mathrm{C}$, and then weighing the dried tissue and empty shells. Survival of oysters was measured on experimental reefs by counting the number of live and dead oysters sampled in cage treatments after 10 mo of exposure. Predation mortality was estimated by counting the number of dead oysters with broken or cracked shells within each treatment. Crab and fish predators usually leave a record of broken and cracked shells as evidence of their predation on oysters (Eggleston 1990, Micheli 1997). Not all oysters killed by predators were accounted for probably because some predator-damaged shells fell through the mesh of the cages. Missing oysters were not included in analyses.

Statistical analyses.-Several different analyses of variance (ANOVA) were used to test whether mean flow speed, sediment deposition, burial of reefs, or the recruitment of oysters differed among reef treatments. Multivariate analysis of variance (MANOVA) was used to compare differences among treatments in the growth, condition index, and mortality of hatchery-raised oysters placed in cages because these response variables were recorded from the same individuals. Before ANOVAs and MANOVAs, normality of data was tested using D'Agostino-Pearson's $K^{2}$ test, independence of error terms were tested with Fisher's exact test, and 
TABLE 1. Summary of analysis of variance (ANOVA and MANOVA) models used to test specific predictions.

\begin{tabular}{|c|c|c|c|c|}
\hline & Prediction & $\begin{array}{l}\text { Response } \\
\text { variable(s) }\end{array}$ & ANOVA & Factor(s) \\
\hline & $\begin{array}{l}\text { Oyster reefs alter local flow } \\
\text { speed }\end{array}$ & flow speed & one-way & $\begin{array}{l}\text { 6-m depth: positions on tall and short } \\
\text { reefs, and away from reefs }\end{array}$ \\
\hline B) & $\begin{array}{l}\text { Flow speed increases with reef } \\
\text { height and elevation on reefs }\end{array}$ & flow speed & "reef type": two-way & $\begin{array}{l}\text { 3-m depth: positions on tall, short, } \\
\text { dredged, and low reefs }\end{array}$ \\
\hline C) & $\begin{array}{l}\text { Sedimentation varies with sea- } \\
\text { son, reef height, and position } \\
\text { on reefs }\end{array}$ & $\begin{array}{l}\text { sediment accumu- } \\
\text { lation }\end{array}$ & $\begin{array}{l}\text { modified "reef type": } \\
\text { three-way }\end{array}$ & $\begin{array}{l}\text { 3-m depth: positions on tall, short, } \\
\text { dredged, and low reefs during win- } \\
\text { ter, spring, summer, and fall }\end{array}$ \\
\hline D) & $\begin{array}{l}\text { Burial of reefs decreases with } \\
\text { reef height }\end{array}$ & $\begin{array}{l}\% \text { of reef buried } \\
\text { after } 16 \mathrm{mo}\end{array}$ & one-way & 3- and 6-m depth: reef height \\
\hline E) & $\begin{array}{l}\text { Recruitment increases with } \\
\text { reef height and elevation on } \\
\text { reefs }\end{array}$ & oyster recruitment & "reef type": two-way & $\begin{array}{l}\text { 3-m depth: positions on tall, short, } \\
\text { dredged, and low reefs }\end{array}$ \\
\hline F) & $\begin{array}{l}\text { Oyster growth, condition, and } \\
\text { survival increase with reef } \\
\text { height and elevation of reefs }\end{array}$ & $\begin{array}{l}\text { shell growth, con- } \\
\text { dition index, to- } \\
\text { tal mortality, } \\
\text { and predation }\end{array}$ & $\begin{array}{l}\text { "reef type": three-way } \\
\text { MANOVA }\end{array}$ & $\begin{array}{l}\text { 3-m depth: positions on tall, short, } \\
\text { dredged, and low reefs, and cage } \\
\text { type }\end{array}$ \\
\hline & $\begin{array}{l}\text { Flow speed varies with water } \\
\text { depth, reef height, and posi- } \\
\text { tion on reefs }\end{array}$ & flow speed & $\begin{array}{l}\text { "reef height-water } \\
\text { depth": three-way }\end{array}$ & $\begin{array}{l}\text { 3- and 6-m depths: positions on tall } \\
\text { and short reefs }\end{array}$ \\
\hline & $\begin{array}{l}\text { Sedimentation varies with } \\
\text { season, water depth, reef } \\
\text { height, and position on reefs }\end{array}$ & $\begin{array}{l}\text { sediment accumu- } \\
\text { lation }\end{array}$ & $\begin{array}{l}\text { modified "reef height- } \\
\text { water depth": four- } \\
\text { way }\end{array}$ & $\begin{array}{l}\text { 3- and 6-m depths: positions on tall } \\
\text { and short reefs during winter, } \\
\text { spring, summer, and fall }\end{array}$ \\
\hline & $\begin{array}{l}\text { Recruitment increases with wa- } \\
\text { ter depth, reef height, and ele- } \\
\text { vation on reefs }\end{array}$ & oyster recruitment & $\begin{array}{l}\text { "reef height-water } \\
\text { depth": three-way }\end{array}$ & $\begin{array}{l}3-\text { and } 6-m \text { depths: position on tall } \\
\text { and short reefs }\end{array}$ \\
\hline J) & $\begin{array}{l}\text { Growth, condition, and surviv- } \\
\text { al vary with water depth, reef } \\
\text { height, and position on reefs }\end{array}$ & $\begin{array}{l}\text { shell growth, con- } \\
\text { dition index, to- } \\
\text { tal mortality, } \\
\text { and predation }\end{array}$ & $\begin{array}{l}\text { "reef height-water } \\
\text { depth": MANOVA } \\
\text { four-way }\end{array}$ & $\begin{array}{l}\text { 3- and 6-m depths: positions on tall } \\
\text { and short reefs and cage type }\end{array}$ \\
\hline
\end{tabular}

Note: Nicknames used in the text to describe statistical tests are given in quotations.

homogeneity of variance was tested using Cochran's test $(\alpha=0.05)$. When data had heterogeneous variances, they were square-root transformed, and tests for homogeneity of variance were repeated. In no cases were variances extremely heterogeneous. Wilks' lambda was used to calculate statistical significance in MANOVA (Manly 1992). Bonferroni's adjustment ( $\alpha$ " $=\alpha / k$; where $k=$ number of times response variable data were used in statistical tests $[k=2$ for this study]; $\left.\alpha^{\prime \prime}=0.025\right)$ was used to determine the level of significance required in ANOVA and MANOVA tests because some data on oyster performance were reused in two different analyses. Significant differences among treatments in MANOVAs were examined using the accompanying univariate ANOVAs for each response variable (Manly 1992). The only treatments effects analyzed in the univariate ANOVAs were those that were statistically significant $(P<0.025)$ in the MANOVAs. Two main types of ANOVAs and MANOVAs analyses were used, "reef type" and "reef height-water depth." The reef type tests were used to determine the effect on response variables of reef height and position on reefs at 3-m water depth only. Comparisons across water depths (3- and 6-m depths) were conducted with reef height-water depth tests to examine the additional effect on response variables of water depth and hydrographics. Post hoc multiple comparison tests were performed on mean response variables using the StudentNewman-Keuls method (SNK) (Day and Quinn 1989).
To test the hypothesis that oyster reefs alter flow, a one-way, fixed-factor ANOVA was used to compare flow speed at different positions (front base, crest, sides, and back base) on tall and short reefs, and at corresponding distances above the seafloor, at 6-m water depth (see Table 1A). To test the hypothesis that flow speed increases with reef height and elevation on the four reef types at 3-m depth, a reef type ANOVA (Table 1B) was used, in which reef height (tall, short, dredged, and low) and position on reef (front base vs. crest) were crossed, fixed factors. To compare sediment deposition on reefs at 3-m depth, a reef type ANOVA with an additional factor, season (6-wk periods in each of the four quarters of the year), was used (Table 1C). A one-way, fixed-factor ANOVA was used to compare the percentage area of experimental reefs at 3- and 6-m depths that was buried beneath sediments after 16-mo exposure in the Neuse River estuary (Table 1D). A reef type ANOVA was used to test whether recruitment varied with reef height and position on reefs (Table 1E). A reef type MANOVA was used to test whether the growth, condition, total mortality, and predation mortality of oysters varied with reef height, position on reef, and cage type at 3-m depth (Table 1F). To test whether flow differed over similar reef types located at 3- and 6-m water depths, flow speed was compared in a modified reef type-water depth ANOVA, in which water depth, reef height, and position on reef (front base, back base, side base, and crest) were all crossed, 
fixed factors (Table 1G). Another type of modified reef type-water depth ANOVA was used to test whether sedimentation varied with season, water depth, reef height, and position on reefs (Table $1 \mathrm{H})$. A reef typewater depth ANOVA was used to test whether recruitment varied with water depth, reef height, and position on reefs (Table 1I). Finally, a reef type-water depth MANOVA was used to test whether the growth, condition, total mortality, and predation mortality of oysters varied with water depth, reef height, position on reef, and cage type (Table $1 \mathrm{~J}$ ).

Multiple linear regression analyses (MLRs) were used to quantify the proportion of the variation in oyster growth and mortality that was explained by flow speed, sedimentation, and hydrographics. Full models containing all potentially important parameters, including mean daily averages and variances of each hydrographic condition, were not possible because of insufficient degrees of freedom. To determine which parameters should be included along with flow and sedimentation rate in the final full model, the average and variance of each hydrographic variable were compared separately in various combinations of backwards elimination MLRs, and nonsignificant variables $(P>0.05)$ were removed. The independent variables of mean daily temperature, salinity, dissolved oxygen concentration (DO), variance in temperature, and number days experiencing hypoxia were placed together with flow speed and mean annual daily sedimentation rate in the final MLR models, which contained either mean growth or total percentage mortality as the dependent variables. Backwards MLRs continued to remove nonsignificant factors present in the full model, and arrived at a reduced model that explained a majority of the variance in the dependent variable among treatments.

\section{RESULTS}

Test of hydrodynamic theory.-Oyster reefs influenced local hydrodynamics in a manner consistent with the principle of continuity (e.g., see Fig. 1). Mean flow speed measured in December 1994, under normal flow conditions, varied among reef types (i.e., tall and short reefs located at $6 \mathrm{~m}$ depth), positions on reefs, and similar elevations in the water column away from reefs (one-way ANOVA, $F_{11,12}=31.41, P=0.0001$ ). Flow speed was $64 \%$ greater on the crest and side (at $1.2-\mathrm{m}$ elevation $)$ of tall reefs $(9.6 \pm 0.4$ and $9.5 \pm 0.4 \mathrm{~cm} / \mathrm{s}$, respectively) and $53 \%$ greater on the crest of short reefs $(9.2 \pm 0.5 \mathrm{~cm} / \mathrm{s})$ than at similar heights above the seafloor away from reefs $(5.8 \pm 0.3 \mathrm{~cm} / \mathrm{s}$ at $2.1 \mathrm{~m}$ in elevation; $6.0 \pm 0.2 \mathrm{~cm} / \mathrm{s}$ at $1.2 \mathrm{~m})$. There was no difference among mean flow speeds occurring at the front bases $(4.0 \pm 0.2 \mathrm{~cm} / \mathrm{s}$ for tall reefs vs. $4.9 \pm 0.4$ $\mathrm{cm} / \mathrm{s}$ for short reefs) and back bases ( $4.8 \pm 0.3 \mathrm{vs} .4 .5$ $\pm 0.7 \mathrm{~cm} / \mathrm{s}$ ) of reefs, and at $30 \mathrm{~cm}$ above the seafloor away from reefs $(3.8 \pm 0.5 \mathrm{~cm} / \mathrm{s}$; SNK, $P>0.05)$. However, flow around the side bases of reefs at $30 \mathrm{~cm}$ height $(6.9 \pm 0.4 \mathrm{~cm} / \mathrm{s}$ for tall reefs vs. $6.2 \pm 0.3 \mathrm{~cm} / \mathrm{s}$ for short reefs) was greater than at the same height away from reefs $(3.8 \pm 0.5 \mathrm{~cm} / \mathrm{s}$; SNK, $P>0.05)$. Consequently, oyster reefs influence flow and do not act solely to provide substrate elevated above the benthic boundary layer. The flow speeds measured on the crests and front bases of tall and short reefs in this test were close to the flow speed measured on tall reefs $(9.6$ $\pm 2 \mathrm{~cm} / \mathrm{s}$ on crests; $4.0 \pm 1.5 \mathrm{~cm} / \mathrm{s}$ on front bases mean $\pm 1 \mathrm{SD})$ and short reefs $(9.2 \pm 1.6 \mathrm{~cm} / \mathrm{s}$ on crests; and $4.9 \pm 1.9 \mathrm{~cm} / \mathrm{s}$ on front bases) during relatively longterm (7 and $34 \mathrm{~d}$ ) sampling periods (Fig. 5B).

\section{Physical conditions on reefs at 3-m depth}

Flow speed.-Flow speed over tall, short, dredged, and low reefs located at 3-m water depth increased with both reef height and elevation on reefs as predicted. In both normal and fast ambient flow speeds in the Neuse River, flow speed over reefs varied with reef height and position on reef (Table 2; reef type ANOVAs, two-way interaction, reef height $\times$ position, $P=0.0001$ for both tests). In normal flow conditions, mean flow speed on the crests of tall and short reefs was similar, but was greater than on the crests of dredged and low reefs (Fig. $6 \mathrm{~A}$; tall $=$ short $>$ dredged $>$ low; SNK, $P<$ $0.05)$. In fast flow conditions, flow speed on the crests of reefs increased sequentially with reef height (Fig. 6B; tall $>$ short $>$ dredged $>$ low; SNK, $P<0.05$ ). Flow speed was always greater on the crests than front bases of reefs (SNK, $P<0.05$ ). A majority of the variance in flow among treatments was explained by position on reef (Table 2; partial $R^{2}=58 \%$ for average flow conditions, and $67 \%$ for high flow speeds).

Sediment deposition.-Sediment was deposited on experimental reefs at a higher rate during fall than other seasons at 3-m water depth (Fig. 7A). Season explained a majority of variance among treatments (Table 3; partial $R^{2}=76 \%$ ). Mean sediment deposition was higher at the front bases than the crests of reefs during fall and winter when deposition rates were greatest (Fig. $7 \mathrm{~A}$; SNK, $P<0.05$ for all contrasts). Overall, sediment deposition rate varied on tall, short, dredged, and low reefs with season (Table 3; reef type ANOVA, $P=$ $0.0001)$, reef height $(P=0.001)$, and position on reef $(P=0.0004)$.

Burial of reefs. - Burial of reefs beneath sediments deposited from suspended load and/or resulting from bedload transport occurred rapidly over the course of the experiment and varied with reef height (Fig. 8A). After only 3 mo exposure, $61 \pm 24 \%$ of the surface area of low reefs $(N=12$, mean $\pm 1 \mathrm{SD})$ was covered by fine-to medium-sized sand. By 16 mo, $91 \pm 7 \%$ of the mean surface area of low reefs and $49 \pm 9 \%$ of dredged reefs were covered. Low reefs had the greatest amount of area buried beneath sediment compared to all reef types after 16 mo exposure (one-way ANOVA, $F_{6,77}=364.91, P=0.0001$, SNK, $\left.P<0.05\right)$. Burial of tall and short reefs never exceeded $27 \pm 4 \%$. Burial occurred mainly around the bases of reefs and usually 
TABLE 2. Results of two-way ANOVAs testing whether flow speed varied over tall, short, dredged, and low reefs located at 3-m water depth. Model A compares data collected during normal ambient flow speeds in the Neuse River. Model B compares data collected during relatively fast ambient flow speeds.

\begin{tabular}{lrrrrr}
\hline \hline \multicolumn{1}{c}{ Source } & df & \multicolumn{1}{c}{ ss } & \multicolumn{1}{c}{$F$} & \multicolumn{1}{c}{$P$} & \multicolumn{1}{c}{ Partial } \\
\hline Model A: Normal flow speeds & & & & \\
Reef height (H) & 3 & 27.47 & 37.75 & 0.0001 & 0.23 \\
$\begin{array}{l}\text { Position on reef (P) } \\
\text { H } \times \text { P }\end{array}$ & 1 & 70.04 & 288.83 & 0.0001 & 0.58 \\
Residual & 3 & 19.07 & 84.74 & 0.0001 & 0.16 \\
Total & 16 & 3.88 & 26.22 & & \\
Model B: Fast flow speed & 23 & 120.46 & & & \\
$\quad$ & & & & & \\
Reef height (H) & 3 & 170.00 & 108.00 & 0.0001 & 0.18 \\
Position on reef (P) & 1 & 624.75 & 1185.00 & 0.0001 & 0.67 \\
H $\times$ P & 3 & 134.22 & 84.74 & 0.0001 & 0.14 \\
$\quad$ Residual & 16 & 8.48 & & & \\
Total & 23 & 937.63 & & & \\
\hline
\end{tabular}

Notes: Main factors were reef height (2-m, 1-m, 0.6-m, and 0.1-m tall) and position on reef (front base and crest). Partial $r^{2}$ (i.e., proportion of variance explained by a factor) $=$ sum of squares (ss) of factor divided by total sum of squares. Data are shown in Fig. 6.

smothered and killed oysters and other sessile organisms living near the reef-sediment interface. In May 1995 , the number of live and dead oysters were counted in five $0.10-\mathrm{m}^{2}$ quadrats placed haphazardly around the base and crest of each of five short reefs located at 3-m depth. The percentage mortality was significantly greater on the buried bases $(97 \pm 6 \%$, mean $\pm 1 \mathrm{SD})$ of reefs than the unburied crests of reefs $(24 \pm 9 \%$, one-way ANOVA, $\left.F_{1,48}=223.00, P=0.001\right)$. Cages containing oysters placed on the base of reefs were never completely buried because they sat on top of the shell material of the reef, which filled in with sediment beneath the cages.
Responses of oysters to physical conditions on reefs

Recruitment.-Oyster larvae settled heavily on the experimental oyster reefs between August and October 1994 (Fig. 9A). Mean recruitment did not differ between tall, short, dredged, and low reefs at 3-m depth (reef type ANOVA, $F_{3,40}=1.24, P=0.31$ ). There was a trend toward greater recruitment on the front bases $\left(184.6 \pm 54.3 / 0.16 \mathrm{~m}^{2}\right.$, mean $\left.\pm 1 \mathrm{SD}\right)$ than crests $(156.3$ \pm 44.8 ) of reefs, but the difference between positions was not statistically significant $\left(F_{1,40}=3.92, P=\right.$ $0.055)$.

Growth, condition, and survival.-Mean growth in shell height, condition index, total percentage mortal-

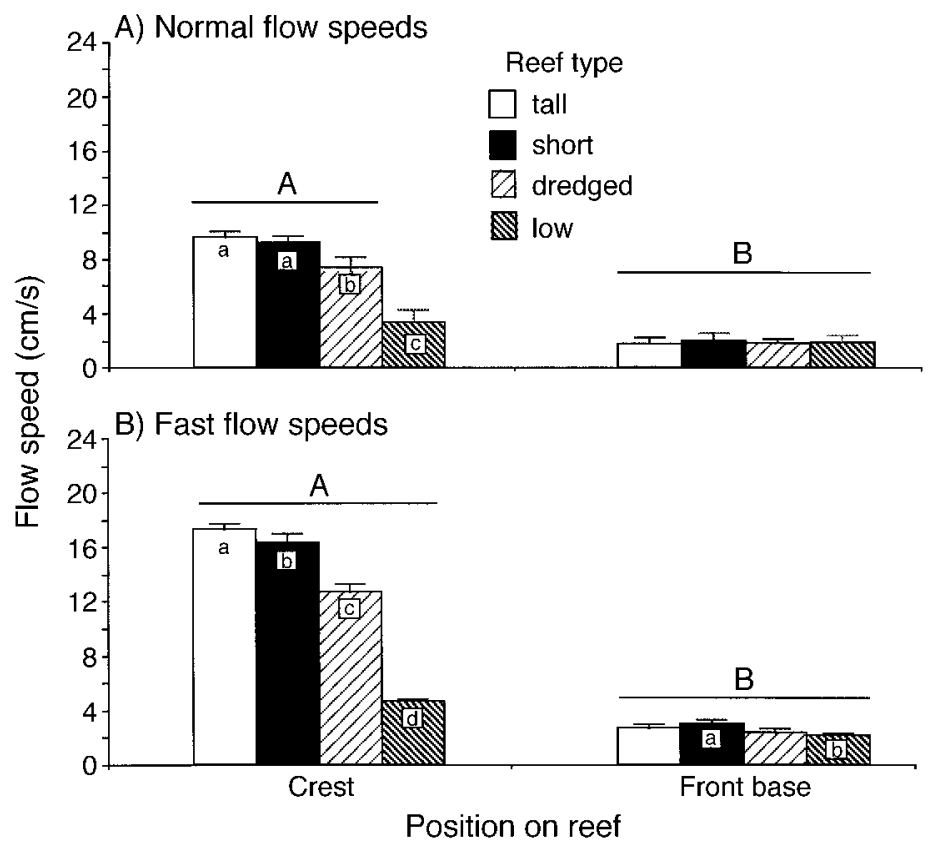

FIG. 6. Flow speeds measured at two positions (front base and crest), under two flow conditions ("normal" and "fast"), on experimental oyster reefs (tall, short, dredged, and low) located at 3-m water depth. (A) Normal flow refers to an ambient flow speed (at 1-m elevation away from reefs) of $5.9 \pm 0.5 \mathrm{~cm} / \mathrm{s}$. (B) Fast flow refers to an ambient flow speed of $11.5 \pm$ $1.3 \mathrm{~cm} / \mathrm{s}$. Data shown are mean $(+1 \mathrm{SE})$ flow speeds measured over three replicate reef-type $X$ position-on-reef combinations. Flow speed varied in both flow conditions with reef height and position on reef. Means with different letters are significantly different (SNK, $P<0.05$ ). Capital letters refer to differences between positions, and lowercase letters refer to withinposition differences among reef types $(\mathrm{A}>\mathrm{B}$, and $\mathrm{a}>\mathrm{b}>\mathrm{c}>\mathrm{d}$ ). 


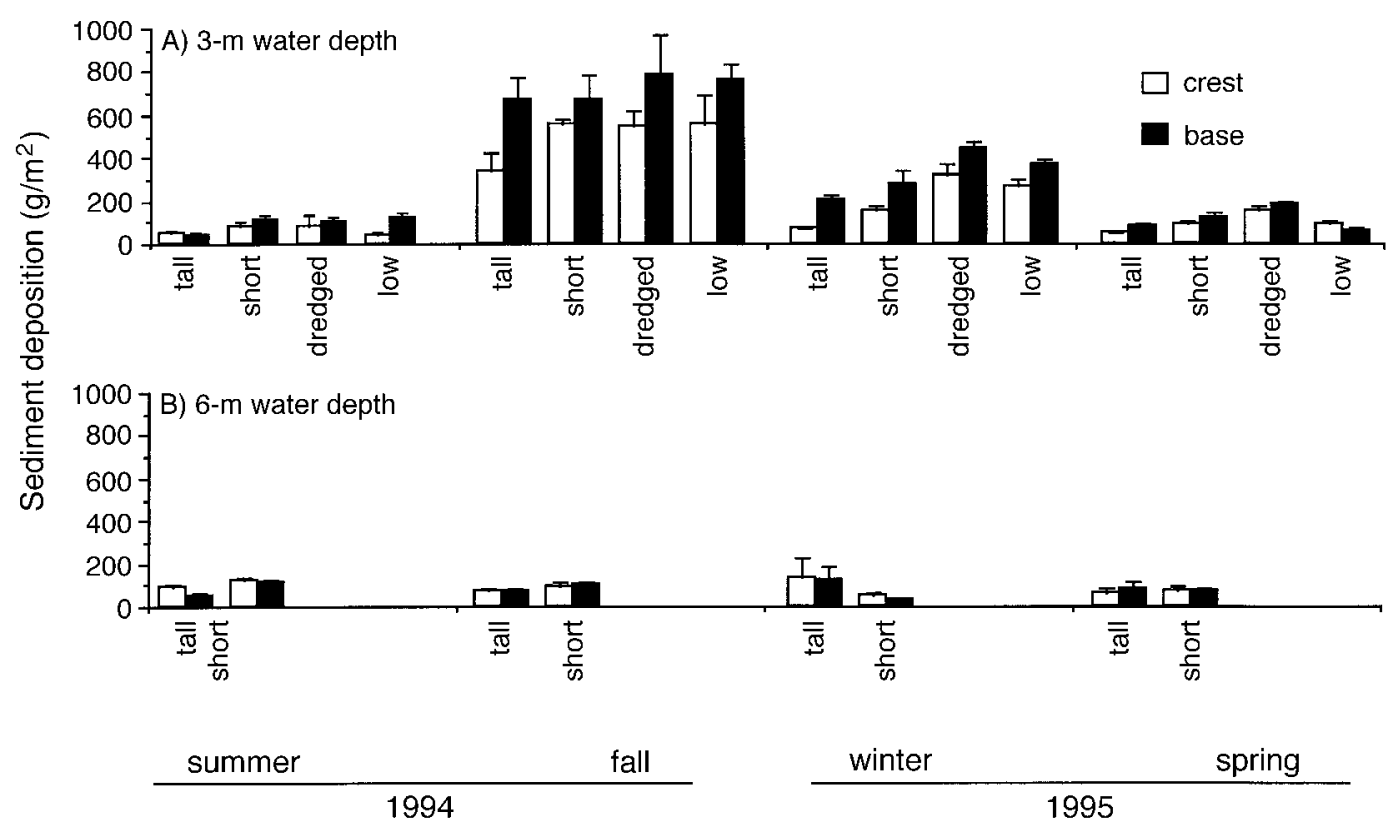

FIG. 7. Mean (+1 SE) sediment deposition measured in sediment traps (diameter of opening $\left.=0.008 \mathrm{~m}^{2}\right)$ placed on the front bases and crests of experimental reefs $(N=3)$ at 3- and 6-m depths during 6-wk periods in each of four seasons. Data were converted to represent sediment deposition per $1 \mathrm{~m}^{2}$.

ity, and percentage predation mortality of hatcheryraised oysters varied with reef height and position on reefs (Table 4; reef type MANOVA, two-way interaction, reef height $\times$ position, $P=0.0001)$ and with cage type $(P=0.0001)$ at 3 -m water depth. In general, growth and condition index increased with reef height and elevation on reefs, as did flow speed, while mortality showed the opposite pattern. Predation mortality varied only with cage treatment. Mean growth of oysters was higher on the tall and short reefs than the dredged and low reefs (Fig. 10A; tall $=$ short $>$ dredged $>$ low; SNK, $P<0.05)$. The difference in growth with reef height explained most of the variance (54\%) among treatments. Position on reef also had an important effect on growth, explaining $15 \%$ of the vari-

TABLE 3. Results of a three-way ANOVA testing whether sediment deposition rates $\left(\mathrm{g} \cdot \mathrm{m}^{-2} \cdot 6-\mathrm{wk}_{\text {k }}\right.$ period $\left.{ }^{-1}\right)$ varied as a function of season (summer, fall, winter, and spring), reef height (tall, short, dredged, and low), position on reef (front-base and crest), and their interaction.

\begin{tabular}{lrrrrc}
\hline \hline \multicolumn{1}{c}{ Source } & df & \multicolumn{1}{c}{ Ss } & \multicolumn{1}{c}{$F$} & \multicolumn{1}{c}{$P$} & \multicolumn{1}{c}{ Partial } \\
\hline Season (S) & 3 & 25.41 & 64.06 & 0.0001 & 0.74 \\
Reef height (H) & 3 & 2.04 & 13.13 & 0.0001 & 0.06 \\
Position on reef (P) & 1 & 0.75 & 14.48 & 0.0004 & 0.02 \\
S $\times$ H & 9 & 0.81 & 1.78 & 0.09 & ns \\
S $\times$ P & 3 & 0.24 & 1.53 & 0.22 & $\mathrm{~ns}$ \\
$\mathrm{H} \times \mathrm{P}$ & 3 & 0.33 & 2.16 & 0.10 & $\mathrm{~ns}$ \\
$\mathrm{~S} \times \mathrm{H} \times \mathrm{P}$ & 9 & 0.36 & 0.88 & 0.55 & $\mathrm{~ns}$ \\
Residual & 56 & 2.80 & & & \\
Total & 87 & 34.26 & & &
\end{tabular}

Note: Reefs were located at 3-m water depth. Data are shown in Fig. 7A. ance. Growth was greater at the crests of tall and short reefs than at the front bases of all reefs, and the crests of dredged and low reefs (Fig. 10A; SNK, $P<0.05$ for all contrasts). There was no difference in growth

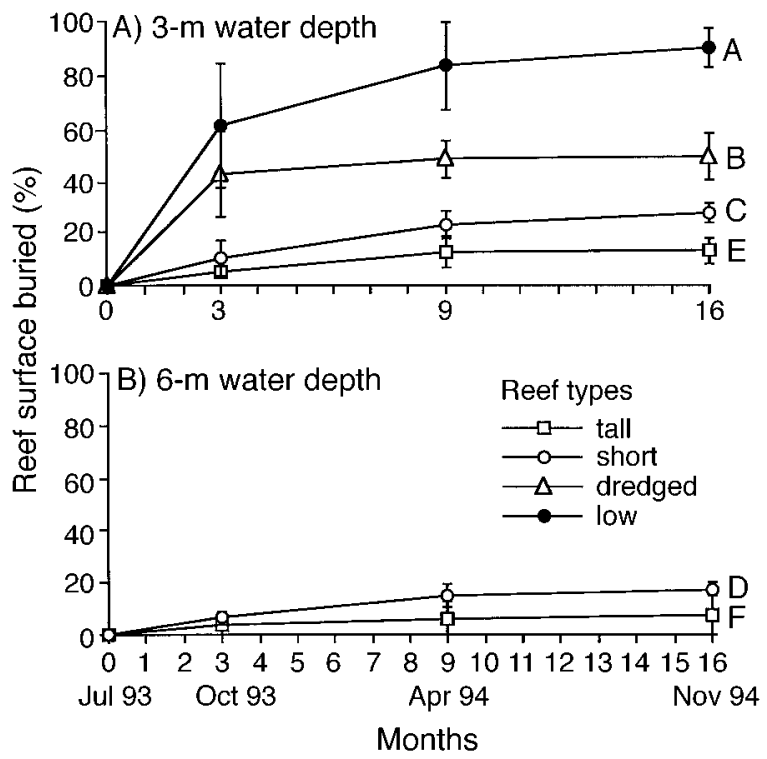

FIG. 8. Percentage of surface area of experimental oyster reefs completely buried beneath sediments over a $16-$ mo period. Reefs were constructed in July 1993. Data are mean $( \pm 1$ SE) percentage burial measured on 12 replicates of each reef type, at each water depth. Percentage burial varied with reef type at $16 \mathrm{mo}$. Letters represent means that were significantly different during the last time period only: $\mathrm{A}>\mathrm{B}>\mathrm{C}>\mathrm{D}$ $>\mathrm{E}>\mathrm{F}(\mathrm{SNK}, P<0.05)$. 


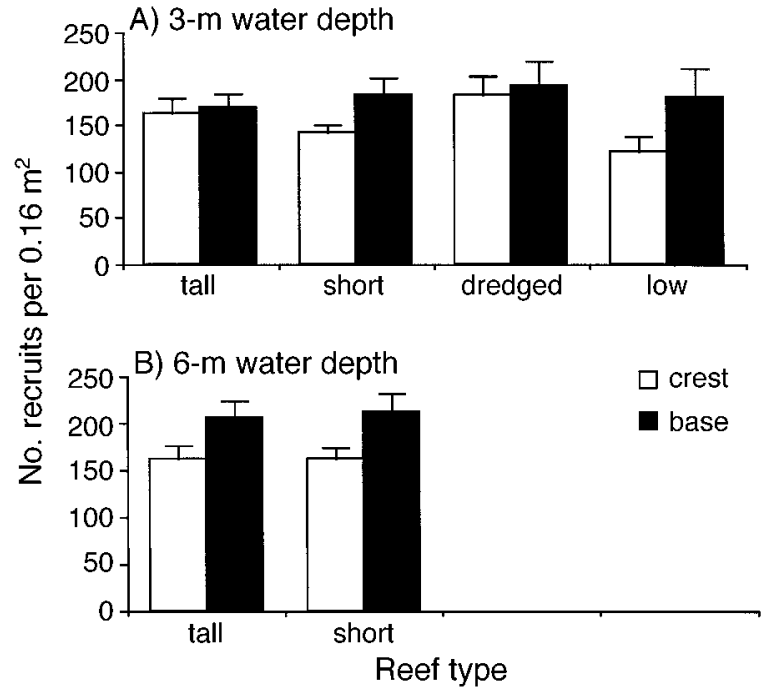

FIG. 9. Recruitment of oysters on experimental oyster reefs in October 1994. Recruitment substrates $\left(0.16 \mathrm{~m}^{2}\right)$ were deployed in August 1994 and collected 2 mo later. Data represent mean $(+1 \mathrm{SE})$ recruitment measured on six replicate reef-type $\times$ position-on-reef combinations. Recruitment was significantly greater on the front bases than crests of tall and short reefs at 3- and 6-m depths.

between positions on dredged and low reefs (SNK, $P$ $>0.05$ ), where differences in flow speed and sedimentation were smallest. The variation in growth with both reef height and position resulted in an interaction in the ANOVA (Table 4; reef type ANOVA, two-way interaction, reef height $\times$ position, $P=0.0004)$. Growth did not vary with cage type $(P=0.38)$.

Condition index of oysters varied with reef height (Table 4; reef type ANOVA, $P=0.0001$ ) and position on reef $(P=0.0001)$ at $3-\mathrm{m}$ depth. Condition index was greatest on tall and short reefs and lowest overall on low reefs (Fig. 11A; tall $=$ short $>$ dredged $>$ low;

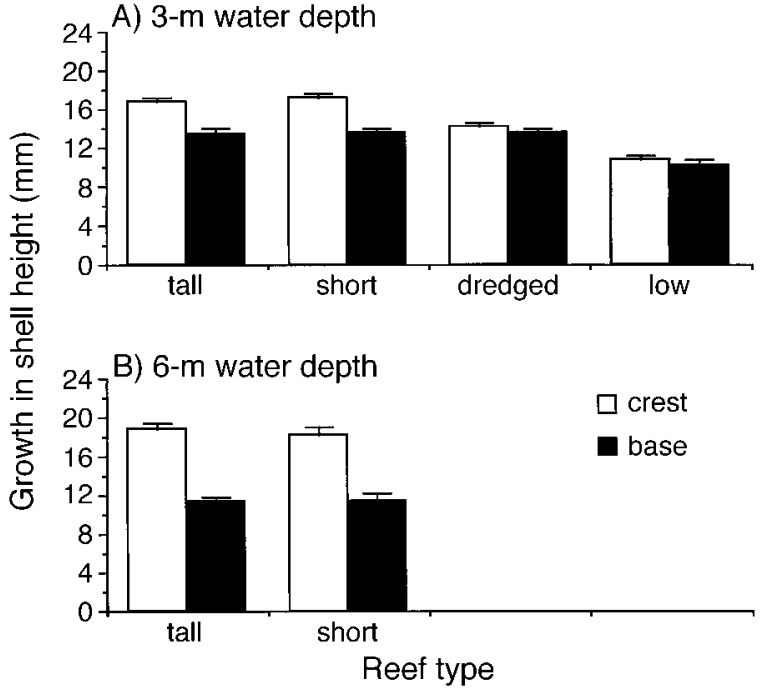

FIG. 10. Growth in shell height (measured umbo to dorsal edge) of caged, hatchery-raised oysters after 10 mo exposure on experimental reefs (June 1995). Data shown represent mean $(+1 \mathrm{SE})$ growth of oysters calculated by pooling data from three of each cage type (cages, cage controls, and corrals) placed as a set on each of three replicate reef-type $X$ position-on-reef combinations. At 3-m depth, growth was significantly greater on tall and short reefs than on dredged and low reefs. At both depths, growth was greater on the crests than the front bases of all reef types (except low reefs).

SNK, $P<0.05)$. Reef height was the most important factor influencing condition index of oysters at 3-m depth, explaining $37 \%$ of the variance among treatments. Position on reef also had an important effect on condition index, explaining $25 \%$ of the variance among treatments $(P=0.0001)$. Condition index was greater on the crests than the front bases of reefs for all reef types except low reefs (SNK, $P<0.05$ ).

Mean total percentage mortality of experimental oys-

TABLE 4. Results of MANOVA comparing the growth $(\mathrm{G})$, condition index (CI), total percentage mortality (M), and percentage predation mortality $(\mathrm{P})$ of hatchery-raised oysters placed on reefs at $3-\mathrm{m}$ water depth.

\begin{tabular}{|c|c|c|c|c|c|c|c|c|c|c|c|c|c|}
\hline \multirow[b]{3}{*}{ Source } & \multicolumn{10}{|c|}{ Univariate ANOVAs } & \multirow{2}{*}{\multicolumn{3}{|c|}{$\begin{array}{r}\text { MANOVA } \\
(\mathrm{G}, \mathrm{CI}, \mathrm{M}, \mathrm{P})\end{array}$}} \\
\hline & \multicolumn{4}{|c|}{ Growth (G) } & \multicolumn{3}{|c|}{ Condition index $(\mathrm{CI})$} & \multicolumn{3}{|c|}{$\%$ Mortality (M) } & & & \\
\hline & $\mathrm{df}$ & $F$ & $P$ & $\begin{array}{l}\text { Partial } \\
r^{2}\end{array}$ & $F$ & $P$ & $\begin{array}{c}\text { Partial } \\
r^{2}\end{array}$ & $F$ & $P$ & $\begin{array}{l}\text { Partial } \\
r^{2}\end{array}$ & $\begin{array}{l}\text { Wilks' } \\
\text { lambda }\end{array}$ & $F$ & $P$ \\
\hline $\begin{array}{l}\text { Reef height } \\
\text { (H) }\end{array}$ & 3 & 50.76 & 0.0001 & 0.54 & 182.37 & 0.0001 & 0.37 & 15.80 & 0.0001 & 0.29 & 0.11 & 13.10 & 0.0001 \\
\hline $\begin{array}{l}\text { Position on } \\
\text { reef }(\mathrm{P})\end{array}$ & 1 & 41.94 & 0.0001 & 0.14 & 123.40 & 0.0001 & 0.25 & 17.84 & 0.0001 & 0.11 & 0.27 & 29.61 & 0.0001 \\
\hline Cage (C) & 2 & 0.97 & 0.38 & $\mathrm{~ns}$ & 4.84 & 0.40 & $\mathrm{~ns}$ & 7.13 & 0.002 & 0.09 & 0.18 & 15.10 & 0.0001 \\
\hline $\mathrm{H} \times \mathrm{P}$ & 3 & 7.33 & 0.0004 & 0.08 & 5.31 & 0.56 & $\mathrm{~ns}$ & 6.49 & 0.001 & 0.12 & 0.38 & 4.37 & 0.0001 \\
\hline $\mathrm{H} \times \mathrm{C}$ & 6 & 2.93 & 0.44 & $\mathrm{~ns}$ & 2.80 & 0.03 & $\mathrm{~ns}$ & 0.38 & 0.89 & $\mathrm{~ns}$ & 0.61 & 0.99 & 0.49 \\
\hline $\mathrm{P} \times \mathrm{C}$ & 2 & 0.68 & 0.99 & ns & 39.15 & 0.58 & $\mathrm{~ns}$ & 1.28 & 0.28 & ns & 0.88 & 0.72 & 0.67 \\
\hline $\mathrm{H} \times \mathrm{P} \times \mathrm{C}$ & 6 & 22.69 & 0.06 & ns & 13.47 & 0.52 & ns & 1.79 & 0.12 & ns & 0.47 & 1.61 & 0.04 \\
\hline Residual & 48 & & & & & & & & & & & & \\
\hline Total & 71 & & & & & & & & & & & & \\
\hline
\end{tabular}

Notes: MANOVA tested whether the four response variables varied as a function of reef height (tall, short, dredged, and low), position on reef (front base vs. crest), cage treatment (cages, controls, and corrals), and their interaction. Shown also are the univariate ANOVAs for each response variable except predation mortality, which was not shown because predation varied $(P=0.0001)$ with cage treatment only. Significant values are in boldface. 


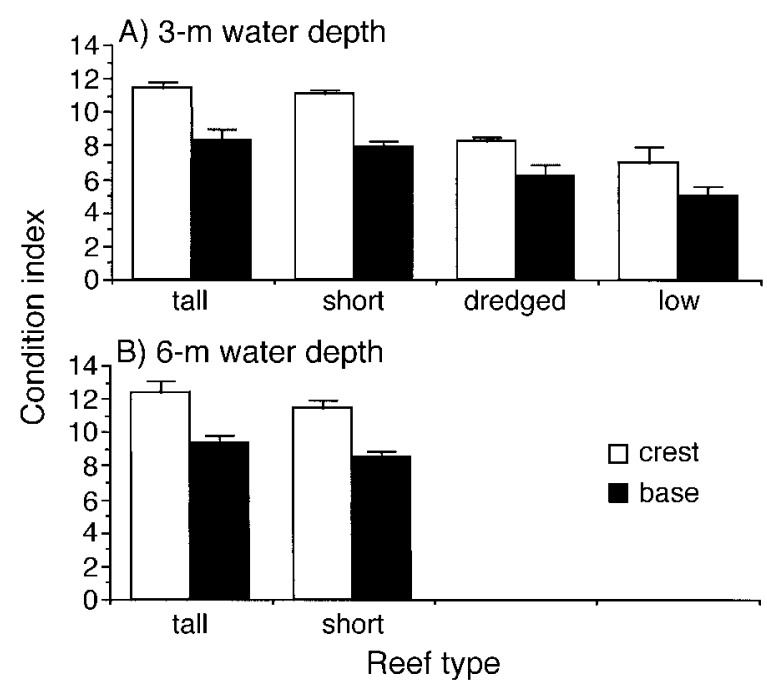

FIG. 11. Condition index (tissue dry mass/[shell mass tissue wet mass]) of caged, hatchery-raised oysters after 10 mo. Data represent mean $(+1 \mathrm{SE})$ condition index of oysters calculated by using the pooling technique described in the caption of Fig. 10. At 3-m depth, condition index was greater on tall and short reefs than on dredged and low reefs. At both depths, condition index was greater on the crests than on the front bases of all reef types (except low reefs).

ters over a 10-mo period at 3-m depth was higher on the front bases than crests of tall, short, and dredged reefs, but was there was no difference in mortality between positions on low reefs (Fig. 12A; Table 4; reef type ANOVA, two-way interaction, reef height $\times$ position, $P=0.001$; SNK, $P<0.05)$. Mortality was also higher across low reefs $(63 \pm 4 \%$, mean $\pm 1 \mathrm{SD})$ than the other reef types (tall $=38 \pm 18 \%$; short $=43 \pm$ $13 \%$; dredged $=48 \pm 15 \%$; SNK, $P<0.05)$. Reef height explained $29 \%$, and position explained $11 \%$, of the variance among treatments. Total mortality also varied with cage treatment $(P=0.002)$. Mortality was greater in cages than in cage controls and corrals (Fig. 13 ; SNK, $P<0.05$ ). However, my estimate of mortality in the cage controls and corrals was conservative because I did not count missing oysters as dead, when in fact some of the missing oysters $(37 \pm 12 \%$ [mean \pm $1 \mathrm{SD}$ ] in cage controls and $24 \pm 17 \%$ in corrals) were likely removed and eaten by predators, especially blue crabs (e.g., Micheli 1997). Percentage of total mortality caused by large predators (Fig. 14A) did not vary with reef height or position on reefs (reef-type ANOVA, reef height, $F_{3,48}=1.26, P=0.29$; position, $F_{1,48}=1.76$, $P=0.19)$ at $3-\mathrm{m}$ depth. However, predation mortality varied with cage treatment $\left(F_{2,48}=86.15, P=0.0001\right)$ as expected: it was lower in cages than in cage controls and corrals (Fig. 15A; SNK, $P<0.05$ ). Predation accounted for nearly one-half of the total mortality in cage controls $(21.1 \%$ predation mortality/[44.4\% total mortality] $=47 \%$ of total mortality due to predation) and corrals $(21.4 \%$ predation mortality/[45.1\% total mortality $]=47 \%$; compare Figs. 13 and 15A). The

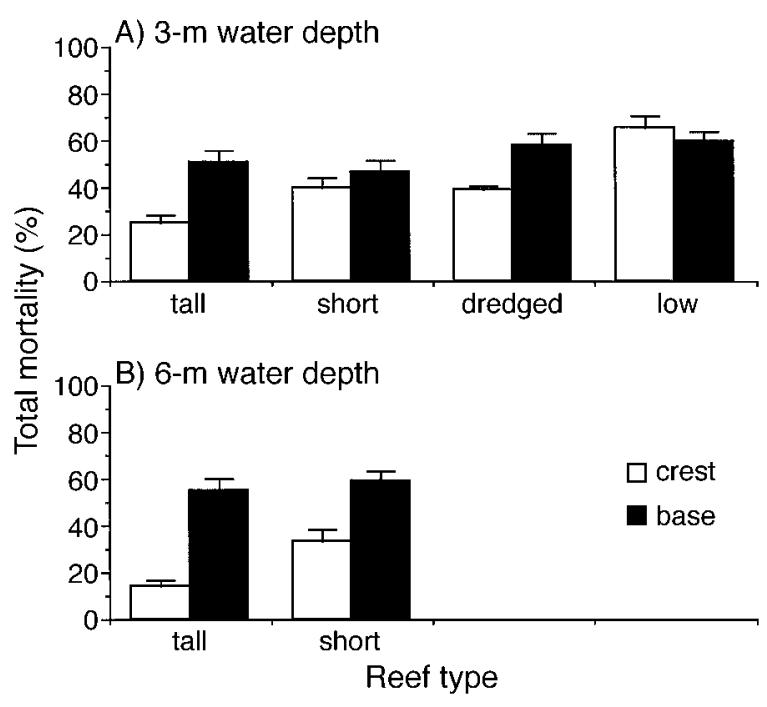

FIG. 12. Percentage total mortality of caged, hatcheryraised oysters after 10 mo. Data represent mean $(+1 \mathrm{SE})$ percentage mortality calculated by using the pooling technique described in the caption of Fig. 10. At 3-m depth, mortality was greatest on low reefs. For all reefs except low reefs, mortality was greater on the front base than on the crest (see Table 4). Mortality was greatest overall on the front bases of reefs at 6-m depth (see Table 5).

difference in total and predation mortality with cage type caused the significant effect of cage treatment in the MANOVA.

Physical conditions and responses of oysters across water depths

Physical conditions.-All of the physical variables measured on tall and short reefs at 3-and 6-m depths changed with water depth, except flow speed. Flow speed, measured during fast ambient flow speeds, did

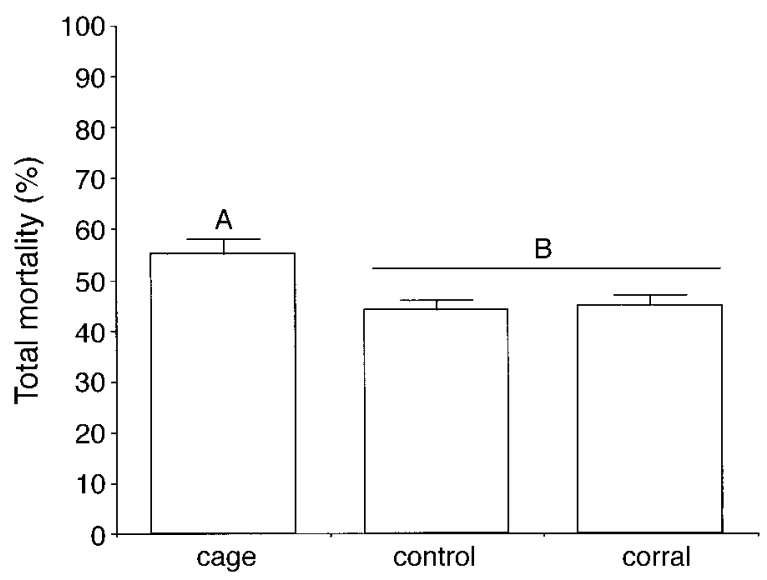

FIG. 13. Mean $(+1 \mathrm{SE})$ percentage total mortality of caged oysters placed in three cage treatments on tall, short, dredged, and low reefs located at 3-m depth. There was a significant effect of cage treatment in the ANOVA $(P=0.002)$. Letters represent means that are significantly different: A $>$ B $(\mathrm{SNK}$, $P<0.05)$ 


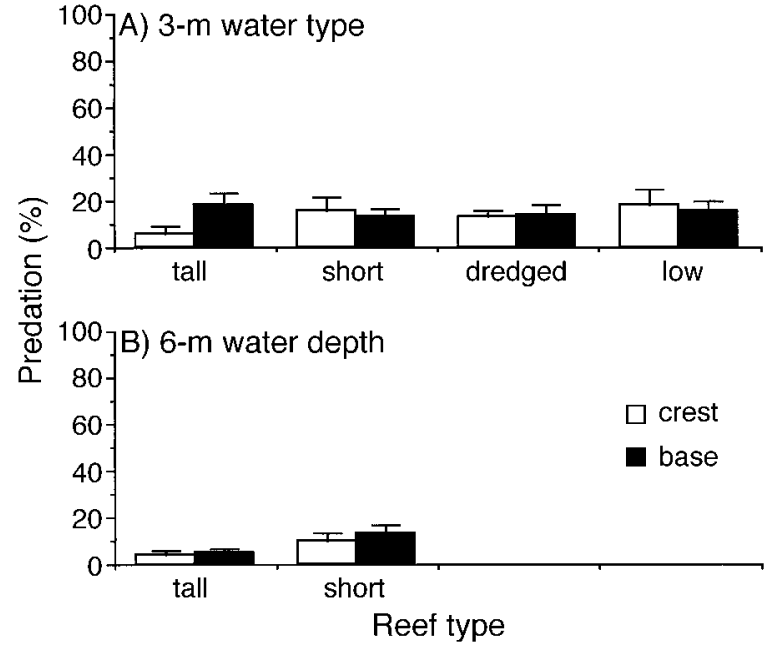

FIG. 14. Percentage of total mortality of caged oysters on experimental reefs caused by crab and fish predation after 10 mo. Data represent mean $(+1 \mathrm{SE})$ percentage predation mortality calculated by using pooling techniques described in the caption of Fig. 10.

not differ with water depth as hypothesized (reef height-water depth ANOVA, $F_{1,32}=2.73, P=0.11$ ). Instead, flow varied with reef height and position on reefs (two-way interaction, reef height $\times$ position, $F_{3,32}$ $=6.40, P=0.002$ ), as it did on the four reef types located at 3-m depth. Flow was higher on the crests than front bases of reefs (SNK, $P<0.05$ ), and position on reef explained most of the variance among treatments (95\%). Sedimentation at 3- and 6-m depths varied with season, water depth, and position on reef (reef height-water depth ANOVA, two-way interactions, season $\times$ depth, $F_{3,56}=14.97, P=0.0001$; season $\times$ position, $\left.F_{3,56}=4.14, P=0.001\right)$. Sedimentation was (1) greater at 3-than 6-m depth, but only in the fall (Fig. 7), and (2) was greater on the front bases than crests of reefs, but only in the fall (SNK, $P<0.05$ for all contrasts). Tall and short reefs at 6-m depth expe- rienced moderately lower levels of burial than did the same reef types at 3-m depth (Fig. 8; SNK, $P<0.05$ ).

Monitoring of hydrographic conditions revealed large variations in water temperature $(T)$, salinity $(S)$, and dissolved oxygen concentrations (DO) through time around experimental oyster reefs at 3- and 6-m depths between August 1994 and July 1995 (Fig. 16). In general, daily and seasonal variations in $T$ were higher than those for $S$. DO exhibited relatively high daily variation, especially near the seafloor at 6-m depth. DO dropped to very low levels when the water column was temperature or density (i.e., salinity) stratified. Time series, ranges, and means $( \pm 1 \mathrm{SD})$ of $S, T$, and DO measured in the vicinity of experimental oysters are provided in Fig. 16. The most dramatic difference in hydrographic conditions among experimental reef treatments was the total (but not necessarily continuous) number of days spent in hypoxia (i.e., $<2 \mathrm{mg}$ $\mathrm{O}_{2} / \mathrm{L}$ ). Oysters at the bases of the tall and short reefs located at the $6-\mathrm{m}$ station were exposed to a total of $26 \mathrm{~d}$ of hypoxia/anoxia during 1995. Oysters at all other locations were exposed to no more than a total of $5 \mathrm{~d}$ of hypoxia. The majority of days in which oysters experienced hypoxia occurred in May and June 1995, when winds blew at velocities consistently less than $2.5 \mathrm{~m} / \mathrm{s}$ (National Weather Service 1996), conditions that eliminate wind mixing of the water column causing strong vertical temperature and density stratification in the Neuse River estuary (Wells and Kim 1989).

Responses of oysters.-All measures of oyster performance changed only slightly with water depth in the Neuse River estuary, except recruitment, which did not vary with depth. On tall and short reefs at 3- and 6-m depths, there was no difference in recruitment with water depth (reef height-water depth ANOVA, $F_{1,40}=$ $2.83, P=0.10)$ or reef height $\left(F_{1,40}=0.004, P=0.95\right)$. However, recruitment was greater on the front bases $(193.5 \pm 44.6)$ than the crests $(159.4 \pm 31.0)$ of reefs (Fig. 9; $F_{1,40}=9.38, P=0.004$; SNK, $P<0.05$ ). The growth, condition index, total percentage mortality, and

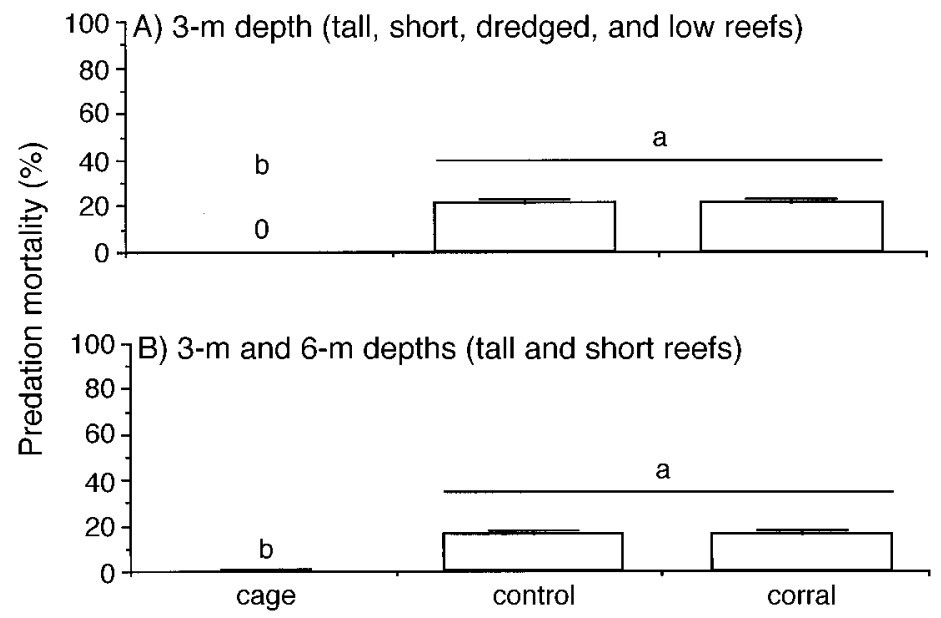

FIG. 15. Mean (+1 SE) percentage of total mortality of caged oysters on experimental reefs caused by crab and fish predation. (A) Effect of cage treatments on tall, short, dredged, and low reefs at 3-m depth. (B) Effect of cage treatments on tall and short reefs at 3- and 6-m depths. Letters represent means that are significantly different: a $>$ b, SNK, $P<0.05$. 

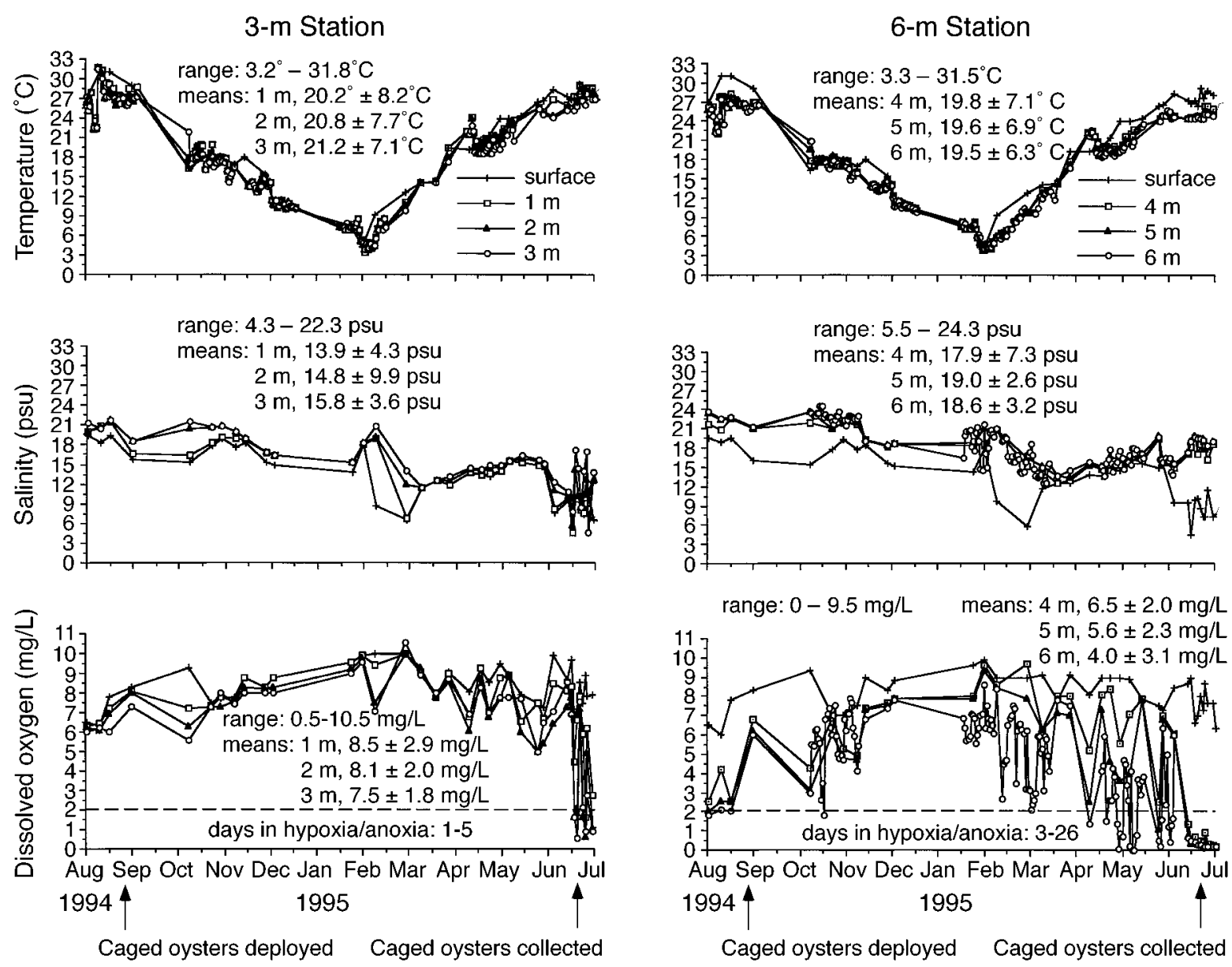

FIG. 16. Water temperature, salinity, and dissolved oxygen around experimental oyster reefs located at 3- and 6-m water depths in the Neuse River estuary. Hypoxic/anoxic conditions for oysters existed below the dashed line at $<2 \mathrm{mg} / \mathrm{L}$. Given also are the ranges and means $( \pm 1 \mathrm{SD})$. Means are grand means of all daily means (daily mean $=$ mean of all measurements taken over a $24-\mathrm{h}$ sampling interval).

percentage predation of hatchery-raised oysters varied with water depth and position on reefs (Table 5; reef height-water depth MANOVA, two-way interaction, water depth $\times$ position, $P=0.0001)$, reef type $(P=$ $0.0003)$, and cage treatment $(P=0.0001)$. Growth of experimental oysters was greater on the crests of reefs at 6-m depth $(18.5 \pm 0.7 \mathrm{~mm})$ than at $3-\mathrm{m}$ depth $(17.0$ $\pm 1.3 \mathrm{~mm})$, but growth on the front bases of reefs was lower at $6-\mathrm{m}(11.3 \pm 1.2 \mathrm{~mm})$ than at $3-\mathrm{m}$ depth $(13.5$ $\pm 1.4 \mathrm{~mm}$; Fig. 10; Table 5 reef height-water depth ANOVA, two-way interaction, water depth $\times$ position, $P=0.0001$; SNK, $P<0.05)$. Despite differences across depth, position on reef explained most of the variance in growth amongst treatments $(76 \%)$. Like that for shell growth, most of the variance $(67 \%)$ in mean condition index of oysters was explained by position on reef. Condition index was much higher at the crests than front bases of both reef types at both water depths (Fig. 11; SNK, $P<0.05$ ). A four-way interaction among factors in the ANOVA (Table 6; reef heightwater depth ANOVA, four-way interaction among fac- tors, $P=0.011)$ resulted from a complexity of differences in condition index among cage controls and corrals located at different positions. However, the fourway interaction explained only $2 \%$ of the variance among treatments. Mean total percentage mortality of oysters was greater on the front bases than crests of both reef types at both depths (SNK, $P<0.05)$. However, mortality was greater on the front bases of reefs at 6-m than at 3-m depth (Fig. 12; Table 6; reef heightwater depth ANOVA, two-way interaction, water depth $\times$ position, $P=0.001$; SNK, $P<0.05$ ). Total mortality was also relatively low on the crests of tall reefs at 6-m depth compared with other treatments (two-way interaction, reef height $\times$ position, $P=0.01$ ). Overall, position on reefs explained most of the variance in total mortality among treatments (43\%). Finally, mean percentage of oyster mortality caused by predation varied only with cage treatment on tall and short reefs located at 3- and 6-m water depths (Fig. 15B; reef height-water depth ANOVA, $F_{2,48}=29.84, P=0.0001$; cages $<$ controls and corrals; SNK, $P<0.05$ ). 
TABLE 5. Results of MANOVA comparing the growth $(\mathrm{G})$, condition index (CI), total percentage mortality (M), and percentage predation mortality $(\mathrm{P})$ of hatchery-raised oysters placed on reefs at 3- and 6-m water depth.

\begin{tabular}{|c|c|c|c|c|c|c|c|c|c|c|c|c|c|}
\hline \multirow[b]{3}{*}{ Source } & \multirow[b]{3}{*}{ df } & \multicolumn{9}{|c|}{ Univariate ANOVAs } & \multirow{2}{*}{\multicolumn{3}{|c|}{$\begin{array}{l}\text { MANOVA } \\
(\mathrm{G}, \mathrm{CI}, \mathrm{M})\end{array}$}} \\
\hline & & \multicolumn{3}{|c|}{ Growth $(\mathrm{G})$} & \multicolumn{3}{|c|}{ Condition index $(\mathrm{CI})$} & \multicolumn{3}{|c|}{$\%$ Mortality (M) } & & & \\
\hline & & $F$ & $P$ & $\begin{array}{c}\text { Partial } \\
r^{2}\end{array}$ & $F$ & $P$ & $\begin{array}{c}\text { Partial } \\
r^{2}\end{array}$ & $F$ & $P$ & $\begin{array}{c}\text { Partial } \\
r^{2}\end{array}$ & $\begin{array}{l}\text { Wilks' } \\
\text { lambda }\end{array}$ & $F$ & $P$ \\
\hline $\begin{array}{l}\text { Water depth } \\
\text { (D) }\end{array}$ & 1 & 1.37 & 0.25 & ns & 20.03 & 0.0001 & 0.05 & 0.00 & 0.99 & $\mathrm{~ns}$ & 0.69 & 6.97 & 0.0006 \\
\hline $\begin{array}{l}\text { Reef height } \\
\text { (H) }\end{array}$ & 1 & 0.01 & 0.94 & ns & 12.96 & 0.001 & 0.03 & 8.14 & 0.01 & 0.05 & 0.70 & 6.64 & 0.0008 \\
\hline $\begin{array}{l}\text { Position on } \\
\text { reef }(\mathrm{P})\end{array}$ & 1 & 327.00 & 0.0001 & 0.76 & 289.00 & 0.001 & 0.67 & 67.13 & 0.0001 & 0.43 & 0.06 & 223.31 & 0.0001 \\
\hline Cage (C) & 2 & 0.53 & 0.59 & ns & 3.94 & 0.03 & 0.02 & 1.68 & 0.20 & ns & 0.70 & 2.28 & 0.04 \\
\hline $\mathrm{D} \times \mathrm{H}$ & 1 & 1.22 & 0.28 & ns & 1.68 & 0.20 & ns & 1.02 & 0.32 & $\mathrm{~ns}$ & 0.90 & 1.60 & 0.20 \\
\hline $\mathrm{D} \times \mathrm{P}$ & 1 & 39.43 & 0.0001 & 0.09 & 0.18 & 0.67 & ns & 8.14 & 0.001 & 0.05 & 0.47 & 16.99 & 0.0001 \\
\hline $\mathrm{D} \times \mathrm{C}$ & 2 & 0.00 & 0.99 & $\mathrm{~ns}$ & 0.01 & 0.92 & ns & 7.63 & 0.01 & 0.05 & 0.86 & 1.22 & 0.30 \\
\hline $\mathrm{H} \times \mathrm{P}$ & 1 & 0.24 & 0.78 & ns & 2.91 & 0.06 & ns & 0.88 & 0.42 & $\mathrm{~ns}$ & 0.86 & 2.46 & 0.07 \\
\hline $\mathrm{H} \times \mathrm{C}$ & 2 & 0.19 & 0.83 & ns & 7.84 & 0.001 & 0.04 & 0.15 & 0.86 & ns & 0.74 & 2.52 & 0.03 \\
\hline $\mathrm{P} \times \mathrm{C}$ & 2 & 0.60 & 0.55 & ns & 2.64 & 0.08 & ns & 0.64 & 0.53 & ns & 0.83 & 1.44 & 0.21 \\
\hline $\mathrm{D} \times \mathrm{H} \times \mathrm{P}$ & 1 & 0.92 & 0.34 & ns & 0.07 & 0.80 & ns & 0.14 & 0.71 & ns & 0.99 & 0.14 & 0.93 \\
\hline $\mathrm{D} \times \mathrm{H} \times \mathrm{C}$ & 2 & 0.28 & 0.75 & ns & 3.24 & 0.06 & ns & 0.99 & 0.15 & ns & 0.83 & 1.51 & 0.18 \\
\hline $\mathrm{D} \times \mathrm{P} \times \mathrm{C}$ & 2 & 2.03 & 0.14 & ns & 0.95 & 0.40 & ns & 1.96 & 0.15 & ns & 0.85 & 1.32 & 0.25 \\
\hline $\begin{array}{l}\mathrm{H} \times \mathrm{P} \times \mathrm{C} \\
\mathrm{D} \times \mathrm{H} \times \mathrm{P}\end{array}$ & 2 & 2.17 & 0.13 & ns & 1.83 & 0.17 & ns & 0.88 & 0.42 & ns & 0.81 & 1.73 & 0.12 \\
\hline $\begin{array}{l}\times \mathrm{C} \\
\text { Residual }\end{array}$ & $\begin{array}{r}2 \\
48\end{array}$ & 0.54 & 0.59 & ns & 5.12 & $\mathbf{0 . 0 1}$ & 0.02 & 1.35 & 0.27 & ns & 0.76 & 2.26 & 0.05 \\
\hline Total & 71 & & & & & & & & & & & & \\
\hline
\end{tabular}

Notes: MANOVA tested whether the four response variables varied as a function of water depth, reef height (tall, short, dredged, and low), position on reef (front base vs. crest), cage treatment (cages, controls, and corrals), and their interaction. Shown also are the univariate ANOVAs for each response variable except predation mortality, which was not shown because predation varied $(P=0.0001)$ with cage treatment only. Significant values are in boldface.

TABLE 6. Results of backward multiple linear regression analysis performed on oyster growth data.

\begin{tabular}{|c|c|c|c|c|c|c|}
\hline Source & df & MS & $\begin{array}{l}\text { Partial } \\
F \text { ratio }\end{array}$ & $F$ ratio & $P$ & $r^{2}$ \\
\hline \multicolumn{7}{|l|}{ Complete model $\dagger$} \\
\hline $\begin{array}{l}\text { Regression } \\
\text { Residual } \\
\text { Total }\end{array}$ & $\begin{array}{r}7 \\
6 \\
13\end{array}$ & $\begin{array}{r}13.40 \\
1.91\end{array}$ & & 7.03 & 0.01 & 0.89 \\
\hline $\begin{array}{l}\text { Temperature } \\
\text { Temperature variance } \\
\text { Salinity } \\
\text { Dissolved oxygen } \\
\text { Days in hypoxia } \\
\text { Flow speed } \\
\text { Sedimentation rate }\end{array}$ & & & $\begin{array}{r}0.18 \\
1.09 \\
0.08 \\
0.69 \\
0.11 \\
11.09 \\
0.89\end{array}$ & & $\begin{array}{l}0.68 \\
0.34 \\
0.78 \\
0.44 \\
0.75 \\
0.02 \\
0.38\end{array}$ & \\
\hline \multicolumn{7}{|l|}{ Reduced model $\ddagger$} \\
\hline $\begin{array}{l}\text { Regression } \\
\text { Residual } \\
\text { Total } \\
\text { Flow }\end{array}$ & $\begin{array}{r}1 \\
12 \\
13\end{array}$ & $\begin{array}{r}85.12 \\
1.68\end{array}$ & 50.72 & 50.72 & 0.0001 & 0.81 \\
\hline
\end{tabular}

Notes: The complete model includes all seven independent variables, and the reduced model includes only the variables providing the best fit. Terms in each model equation are the intercept and parameter estimates. Summary statistics are next presented with the degrees of freedom, mean square, $F$ ratio, and $P$ value for the complete model, and the proportion of the variance explained $\left(r^{2}\right)$ by the complete model. Finally, parameters and their variance ratios (partial $F$ ratio) and $P$ values for the partial $F$ tests performed on the separate factors of the model are presented.

$\dagger$ Growth $=89.85-2.77$ (temperature) -0.63 (temperature variance) -0.52 (salinity) + $2.02(\mathrm{DO})+0.14$ (days hypoxia) +0.46 (flow speed $)+0.90$ (sediment rate) .

$\ddagger$ Growth $=10.76+30.6$ (flow speed) . 
TABLE 7. Results of backward multiple linear regression analysis performed on oyster mortality data (mean total \% mortality).

\begin{tabular}{|c|c|c|c|c|c|c|}
\hline Source & df & MS & $\begin{array}{l}\text { Partial } \\
F \text { ratio }\end{array}$ & $F$ ratio & $P$ & $r^{2}$ \\
\hline \multicolumn{7}{|l|}{ Complete model $\dagger$} \\
\hline $\begin{array}{l}\text { Regression } \\
\text { Residual } \\
\text { Total }\end{array}$ & $\begin{array}{r}7 \\
6 \\
13\end{array}$ & $\begin{array}{l}0.04 \\
0.01\end{array}$ & & 4.68 & 0.04 & 0.84 \\
\hline $\begin{array}{l}\text { Temperature } \\
\text { Temperature variance } \\
\text { Salinity } \\
\text { Dissolved oxygen } \\
\text { Days in hypoxia } \\
\text { Flow speed } \\
\text { Sedimentation rate }\end{array}$ & & & $\begin{array}{l}0.17 \\
0.07 \\
0.03 \\
0.44 \\
0.50 \\
3.34 \\
0.10\end{array}$ & & $\begin{array}{l}0.69 \\
0.69 \\
0.88 \\
0.53 \\
0.51 \\
0.12 \\
0.76\end{array}$ & \\
\hline \multicolumn{7}{|l|}{ Reduced model $\ddagger$} \\
\hline $\begin{array}{l}\text { Regression } \\
\text { Residual } \\
\text { Total } \\
\text { Flow }\end{array}$ & $\begin{array}{r}1 \\
12 \\
13\end{array}$ & $\begin{array}{l}0.25 \\
0.005\end{array}$ & 51.37 & 51.37 & 0.0001 & 0.81 \\
\hline
\end{tabular}

Notes: The complete model includes all seven independent variables, and the reduced model includes only the variables providing the best fit. Terms in each model equation are the intercept and parameter estimates. Summary statistics are next presented with the degrees of freedom, mean square, $F$ ratio, and $P$ value for the complete model, and the proportion of the variance explained $\left(r^{2}\right)$ by the complete model. Finally, parameters and their variance ratios (partial $F$ ratio) and $P$ values for the partial $F$ tests performed on the separate factors of the model are presented.

$\dagger$ Mortality $=3.20-0.17$ (temperature) +0.01 (temperature variance) -0.02 (salinity) + 0.10 (dissolved oxygen $)+0.02$ (days hypoxia) -0.02 (flow speed) -0.02 (sedimentation rate)

\$ Growth $=0.62-0.02$ (flow speed)

Regression analyses.-Multiple linear regression analyses (MLR) were used to quantify the proportion of variation in oyster growth and survival explained by hydrographic conditions, flow speed, and mean sedimentation rate across experimental treatments. The full model MLR for both mean growth and total mortality contained water temperature $(T)$, variance in $T$, salinity $(S)$, dissolved oxygen concentration (DO), number days of hypoxia $\left(<2 \mathrm{mg} \mathrm{O}_{2} / \mathrm{L}\right)$, flow speed, and annual mean daily sedimentation rate $(\mathrm{g} / \mathrm{m})$ averaged over the entire 10 mo of the experiment. Results of the backwards MLR revealed that the reduced model that best explained the variance in mean growth and total mortality contained only one parameter, flow speed (Tables 6 and 7). For both mean growth and mean total percentage mortality, the reduced models explained $81 \%$ of the variance among treatments. The complete model for growth explained only $8 \%$ more of the variance in mean growth among treatments than the reduced model (Table 6), while the complete model for mortality only explained $3 \%$ more of the variance (Table 7). Flow speed did not covary with any other factor used in the MLR $\left(R^{2}=0-0.18 ; P=0.14-0.94\right)$. Flow was not negatively correlated with sedimentation in the MLRs because annual mean sedimentation rates were used. Flow was negatively correlated with sedimentation on reefs at 3-m depth in the fall $\left(R^{2}=0.78\right.$; $P=0.001)$ and winter $\left(R^{2}=0.76 ; P=0.002\right)$.

\section{Discussion}

Summary of results.-One physical attribute of oyster reef habitat, its height, was found to alter water flow, such that local flow speed increased with reef height and elevation on reefs. In turn, variation in flow speed explained differences in the recruitment, growth, and condition of oysters. Recruitment was generally greatest at the front bases of reefs where flow speed was lowest, but did not change with reef type or water depth. In contrast, the relationship between flow speed and growth and condition of oysters was positive. Both growth and condition index were consistently greatest where flow speed was highest, at the crests of the two tallest reef types ( 2 and $1 \mathrm{~m}$ tall reefs). Changes in the flow environment helped explain differences in sedimentation rate on oyster reefs and burial of the habitat. In turn, sedimentation and burial helped explain the pattern of oyster mortality on reefs: mortality was greatest on the front bases of reefs where sedimentation and burial were greatest. Results of the multiple linear regression (MLR) analyses indicated that differences in hydrographic conditions and sedimentation rate among reef treatments were overall much less important than differences in flow speed. MLR showed that a vast majority of the variance among treatments in both growth and mortality (81\%) was explained by flow speed alone. Hydrographic conditions influenced oyster growth and mortality only slightly (explaining only $3-8 \%$ of variation).

\section{Responses of oysters to physical conditions on reefs}

Recruitment.-Recruitment of oysters on experimental reefs was predicted to be greatest where flow speed was fastest because the delivery rate and settle- 
ment of larvae were expected to increase with flow. Recruitment often increases with current speed in the marine benthic environment due to enhanced larval supply (e.g., Mullineaux and Garland 1993, Sanford et al. 1994). Instead, recruitment of oysters in the Neuse River was highest at the front bases of reefs where flow speed was lowest and the deposition of inorganic matter was greatest. A similar pattern of settlement and recruitment has been observed for starfish inhabiting coral reefs (Black and Moran 1991), and for benthic fishes inhabiting oyster reefs (Breitburg et al. 1995). Oyster recruitment on experimental reefs was potentially driven by the combined effect of flow and larval behavior acting upon larval settlement. Since recruitment was measured over a single interval, $2 \mathrm{mo}$, some discrepancy may exist between the patterns of settlement and recruitment. Nevertheless, the number of shells (mean $\pm 1 \mathrm{SD}$ ) of very small (1-2 $\mathrm{mm}$ in height), early postsettlement oysters that died were greater on the front bases $\left(2412 \pm 327 / 0.16 \mathrm{~m}^{2}\right)$ than crests $(1100 \pm 231)$ of reefs $(N=3$, tall reefs at $6-\mathrm{m}$ water depth sampled 19 September 1993). Therefore, oyster recruitment mirrored oyster settlement, which appeared to be greatest where the deposition of particles was highest, at the front base of reefs. Highest settlement in areas of highest particle deposition suggests that larvae behaved to some degree as passive particles (e.g., Butman et al. 1988). However, since oysters settle and attach most frequently where they detect chemical cues emitted by adult oysters (Turner et al. 1994), it is more likely that the pattern of oyster settlement and recruitment on my reefs resulted from the interaction of passive deposition and chemical stimulation. Alternatively, larvae may have been caught in wakes that form behind reefs, where they were chemically stimulated by sessile oysters, swam downwards, and settled. A similar influence of wakes on the settlement and recruitment of marine larvae have been observed near rocky headlands (Rankin et al. 1994) and on seamounts (Mullineaux and Mills 1997).

There was little evidence to support the prediction that recruitment increases on reefs with water depth. This prediction was based on previous work (Galtsoff 1964) suggesting that larvae concentrate where net flow is upstream in estuaries (i.e., in deep water). Recruitment did not increase with water depth in the Neuse River estuary, although there was slightly higher recruitment on the crests of reefs at 3-m than at 6-m depth (Fig. 9). Results of this experiment suggest that oyster larvae (1) are distributed equally in shallow and deep water in Neuse; (2) move in mass near the benthos; and (3) settle and recruit on oysters on reefs mainly as a function of the flow environment and a behavioral response to chemical cues.

Growth.-Oyster growth and condition on experimental reefs was strongly influenced by the flow environment, undoubtedly because flow directly or indirectly influences many aspects of an oyster's perfor- mance. Four mechanisms help explain increased growth and condition of oysters with increased flow speed. First, flow speed can increase an oyster's feeding rate and efficiency directly by enhancing internal feeding currents. Oysters (and other bivalve molluscs) are active suspension feeders that create internal feeding currents that draw water into their body cavities where suspended food material is captured. In contrast, passive suspension feeders "sieve" the water as it passes through external feeding appendages. A direct, positive relationship between flow and feeding efficiency has usually been observed for passive suspension feeders, such as gorgonian corals (Patterson 1980) and bryozoans (Okamura 1984). For passive feeders, increased flow results in a greater flux and capture rate of food material (Grizzel et al. 1992). For oysters, external currents (up to $\sim 10 \mathrm{~cm} / \mathrm{s}$ ) apparently enhance internal feeding currents, thereby improving the rate of particle capture (Lenihan et al. 1996, and see Wildish and Saulnier 1993). Second, flow over natural bottoms can indirectly increase feeding and growth of suspension feeders through vertical mixing and the transport of suspended food particles (Fréchette et al. 1993). Natural bottoms, such as an oyster bed, are hydrodynamically "rough" (e.g., Nowell and Jumars 1984). Increase in flow speed over rough bottoms increases turbulent mixing, which, in turn, enhances the vertical delivery of food to the bottom (Butman et al. 1994). Vertical (and horizontal) delivery of suspended matter acts to replenish depleted food concentrations that develop in the water surrounding suspension feeders and sustain higher feeding rates and growth of active suspension feeders (Butman et al. 1994). Third, the potential nutritional quality of suspended material available to oysters on reefs was positively correlated with higher flow, at least on two days in which the quality of suspended matter was measured (in July and December 1994; Fig. 17). As Fig. 17 illustrates, the potential nutritional quality (POM/PIM) of suspended matter was higher at the crests than the front bases of tall and short reef types, but there was no difference in the quality of suspended matter across low reefs. I cannot identify a specific mechanism causing the pattern in potential food quality, but differences may have resulted from a variation in POM/PIM in the water column around reefs (e.g., Anders and Lopez 1988), or the effect of flow on the resuspension of particle matter deposited on the seafloor or surface of reefs (Middleton and Southard 1984). Finally, oysters located in relatively low flow apparently suffered greater levels of parasitism than oysters in high flow (Lenihan et al., in press). The prevalence and intensity of parasitic infection by the protozoan Perkinsus marinus were greater at the bases than crests of experimental reefs. It is very likely that the pattern of increased growth and condition with enhanced flow on oyster reefs results from the combined influence of the four mechanisms I have identified. Results of this study sup- 
FIG. 17. Proportion of particulate organic matter (POM) to particulate inorganic matter (PIM) in 1-L water samples collected over experimental reefs in July 1994 and December 1995. Means (+1 SE) were calculated by pooling data from two replicates of each treatment.

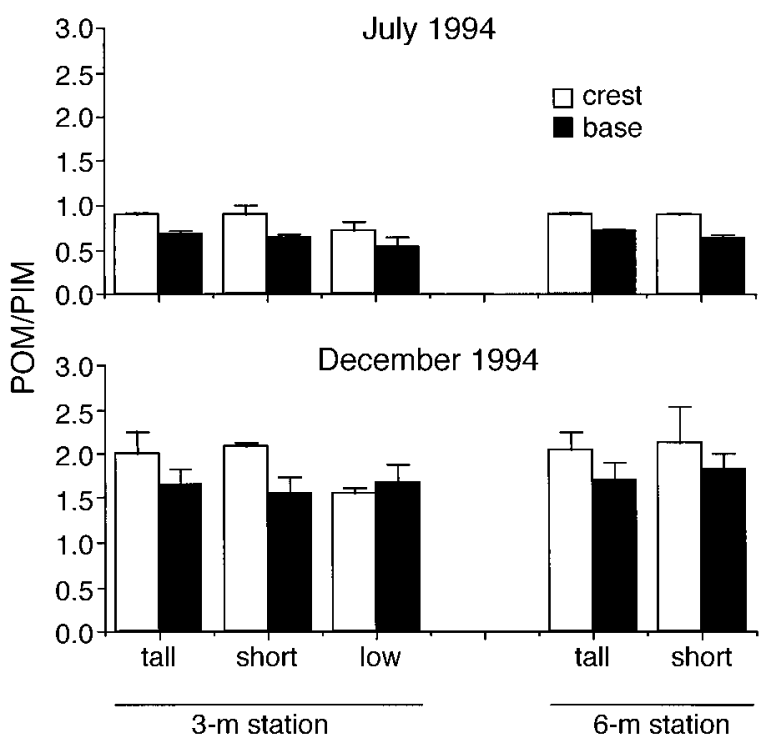

port other work showing that hydrodynamics have a major influence on individual performance (Lenihan et al. 1996, Leichter and Witman 1997), population dynamics (Sanford et al. 1994, Bertness et al. 1998), and community structure (Leichter and Witman 1997, Leonard et al. 1998) of marine benthic organisms.

Mortality.-Flow had a major influence on oyster mortality primarily through its effect on sedimentation processes. During fall and winter, the periods of the heaviest sediment deposition, the mortality of natural populations of oysters was greatest where rates of sedimentation and burial of reef habitat were highest, on low profile reefs and at the bases of other reef types. These were also the locations where mortality of experimental oysters in cages was greatest after $10 \mathrm{mo}$ exposure on reefs (Fig. 14). Burial by sediments and the subsequent mortality of sessile organisms is a common phenomenon on rocky subtidal habitats (Konar and Roberts 1996, Airoldi and Cinelli 1997) and coral reefs (Loya 1976). In contrast to the influence of sedimentation, mortality caused by macropredators (e.g., fishes and crabs) was not likely to have caused the overall patterns in mortality because predation accounted for only $4-20 \%$ of total oyster mortality. Therefore, physical-biological coupling apparently had a greater overall influence on oyster survival in this system than did species interactions.

Influence of hydrographics. - The experimental design of this study allowed for an additional test of whether the location (i.e., water depth) of subtidal oyster reef habitat influenced the individual performance of oysters indirectly by controlling exposure to hydrographic conditions. The relatively high growth of oysters on the crests (Fig. 10B), and high mortality at the front bases (Fig. 12B), of reefs at 6-m water depth suggest that hydrographic conditions may have influenced oyster performance. Oysters at the crests of reefs at 6-m depth experienced less variability in average salinity $(S)$ than oysters on reefs at 3-m depth (Fig. 16). Oysters tend to grow faster and be in better condition with less variation in $S$ (Galtsoff 1964, Shumway 1996). The relatively high mortality of experimental oysters at the bases of reefs at 6-m depth may have resulted from exposure to relatively many (26) days of hypoxia. Results of a related study (Lenihan and Peterson 1998) showed extended periods of bottom hypoxia can cause mass mortality of oysters in the Neuse River estuary. There was no extended period of hypoxia/anoxia during my experiment, but frequent, shortterm low oxygen events may have interacted with reduced food quality, poor oyster condition, and parasitic infection to cause the relatively high mortality of oysters observed at the bases of reefs at $6-\mathrm{m}$ depth. In the marine environment, hydrographic conditions often have strong influence on growth (e.g., Galtsoff 1964, Bayne and Newell 1983, Witman et al. 1993) and mortality (Tenore 1972, Seliger et al. 1985) of sessile organisms. That hydrographics did not have a large influence on oyster growth or mortality in this study may reflect, in part, how very resilient oysters are to fluctuations in environmental conditions (e.g., Shumway 1996).

Implications of enhanced growth rates. - That the physical structure of a biogenic reef habitat controls the local flow environment, and that flow is the dominant factor influencing the performance of oysters is not surprising. What is extraordinary is that under highly variable field conditions, over $80 \%$ of the betweentreatment variation in mean growth and mortality of oysters can be explained by flow speed alone. Clearly, when we consider the expected influence of the physical structure of oyster reefs on oyster population performance, we can focus almost exclusively on how structure controls flow speed. The elegant simplicity 
of this result suggests that one can build tractable models that predict oyster population dynamics for any suite of oyster reefs, as long as the height of the reef habitat is known. A second striking feature of my results is how they translate into implications for oyster population dynamics and production. For instance, the differences in growth rates $(1.4-1.8 \mathrm{~mm} / \mathrm{mo})$ as a function of flow speed was such that oysters at the front bases of reefs, or those on the crests of low profile reefs, will take on average 50 mo until they reach harvest size compared with 39 mo for oysters located on the crests of tall and short reefs. These differences in growth rate (and, additionally, condition index) would translate into parallel differences in reproductive output, and into mortality prior to reproduction. Thus, seemingly small differences in growth rate accumulate in a multiplicative way into greater potential population production and harvests of oysters.

Management recommendations. - The practical motivation for this study was to increase the production of oysters and overall quality of restored oyster reef habitat through better ecological engineering. My results suggest a blueprint for designing long-lasting and more productive oyster reefs, which may improve habitat and fisheries management in estuarine ecosystems. Populations of the eastern oyster have declined for the reasons already described (see Methods: Study organism). In an effort to maintain oyster harvests (and, more recently, essential fish habitat; e.g., Lenihan et al. 1998), habitat managers have restored oyster reefs in estuaries of the Atlantic coast of the United States usually by creating small piles of shells (i.e., low reefs used in this study) or other material (M. Marshall, J. Weston, and M. Luckenbach, personal communication; H. S. Lenihan, personal observation). Little attention has been given to the physical structure of the habitat being created. In North Carolina, reef restoration has not increased oyster production because the animals often die of disease, stress, or predation before reaching harvest size on the restored habitat (Frankenberg 1995). In addition, reefs are rapidly reduced in size by mechanical harvesting gear (Lenihan and Peterson 1998). Faster growth and longer term production of oysters on restored reefs are likely to result when habitat managers build tall reefs. Tall reefs (1-2 $\mathrm{m}$ in height) more closely resemble natural reefs prior to the onset of dredge harvesting at the turn of the century in many estuaries (Rothschild et al. 1994).

The specific recommendation for habitat and fishery managers generated by this study is to restore oyster reefs so that they have sufficient height $(>1 \mathrm{~m})$ to enhance flow speed and diminish sedimentation and burial, which should, in turn, increase the growth, condition, and survival of oysters. Tall restored reefs are likely to maintain sufficient height over multiple harvest seasons to sustain growth rates high enough that oysters reach market size before they die of parasitic infection (e.g., Lenihan et al., in press). The main trade- off to creating tall reefs is a slight decrease in recruitment, which tended to decrease with flow speed. Results of one companion study (Lenihan and Peterson 1998) clearly showed that oyster reefs can be restored in deep portions of estuaries as long as they are tall enough so that the majority of their substrate projects above bottom waters subject to hypoxia/anoxia. By increasing the production of oyster populations and the longevity of restored reef habitat, managers may also more effectively maintain estuarine biodiversity (Wells 1961, Bahr and Lanier 1981, Zimmerman et al. 1989), maintain fisheries production (Arve 1960, Zimmerman et al. 1989, Lenihan et al. 1998), and potentially improve water quality (Newell 1988) in North American estuaries.

\section{CONCLUSION}

Results from this restoration experiment indicate that the physical structure of biogenic reef habitat can modify physical conditions, especially flow, which, in turn, explain a vast majority of the variation in the performance of a resident organism. In the future, when predictions are to be made about how physical habitat structure influences ecological interactions, we must not only consider species-area relationships (e.g., Brown 1971), the availability of niche space (Hutchinson 1961), and the effect of habitat complexity on recruitment (Sale 1991) and predator-prey relationships (Huffaker 1958), but also consider that habitats influence local species indirectly through physical-biological coupling. The relationship between reef habitat form and individual performance clearly indicates that one ecological function of habitat is to modify physical conditions. By understanding specific mechanisms underlying physical-biological coupling, we can better preserve and restore habitat and associated natural resources.

\section{ACKNOWLEDGMENTS}

I thank F. Micheli, C. H. Peterson, and H. C. Summerson for advice, encouragement, support, and reviews of the manuscript. I thank J. E. Byers for help in the field, with experimental designs, statistical analyses, and reviews of the manuscript. I thank M. Marshall, J. French, and the North Carolina Division of Marine Fisheries for helping construct and maintain experimental reefs, and R. Herbert for his many insightful ideas about reef restoration. I thank G. Bath, W. Falls, M. Go, J. Grabowski, A. Maxson, J. Rastafari, G. Safrit, and P. Wyrick for their assistance in the field and laboratory, and for the jellyfish stings they endured. I thank R. Bolser, M. Deal, J. McNinch, and C. Shank for additional help in the field. R. Luettich, J. Hench, and H. Paerl helped with flow and hydrographic measurements. I thank E. Seabloom for help with MANOVAs. Finally, I thank M. Hay, P. Kareiva, R. Luettich, B. Menge, J. Pinckney, J. Wells, and two anonymous reviewers for help with the manuscript. This project was funded by grants from the North Carolina State Legislature through the Cooperative Fisheries Institute (to C. H. Peterson) and the NOAA-Oyster Disease Research Program (to H. S. Lenihan and F. Micheli).

This paper is dedicated to my nephew Joshua Dylan White (1972-1996), a brave and loving young man. 


\section{Literature Cited}

Airoldi, L., and F. Cinelli. 1997. Effects of sedimentation and subtidal macroalgal assemblages: an experimental study of a Mediterranean rocky shore. Journal of Experimental Marine Biology and Ecology 215:269-288.

Ali, S. M. 1981. Effects of inorganic particles on growth of the oyster Crassostrea virginica (Gmelin). Thesis. University of Delaware, Newark, Delaware, USA.

Anders, M. L., and G. Lopez. 1988. The effect of seston on the growth of bivalves at three depths in Long Island Sound. Journal of Shellfish Research 7:146-147.

Arve, R. 1960. Preliminary report on attracting fish by oyster-shell plantings in Chincoteague Bay, Maryland. Chesapeake Science 1:58-65.

Bahr, L. M., and W. P. Lanier. 1981. The ecology of intertidal oyster reefs of the south Atlantic coast: a community profile. U.S. Fish and Wildlife FWS/OBS/81.15. Washington, D.C., USA.

Bayne, T. W., and A. M. Szmant. 1989. Effect of current on the sessile benthic community structure of an artificial reef. Bulletin of Marine Science 44:545-566.

Bell, S. S., E. D. McCoy, and H. R. Mushinsky, editors. 1991. Habitat structure: the physical arrangement of objects in space. Chapman and Hall, London, UK.

Belsky, A. J., R. G. Ammundson, J. M. Duxbury, S. J. Riha, A. R. Ali, and S. M. Mwonga. 1989. The effects of trees on their physical, chemical, and biological environments in semi-arid savannah in Kenya. Journal of Applied Ecology 26:1005-1024.

Bertness, M. D., S. D. Gaines, and S. M. Yeh. 1998. Making mountains out of barnacles: the dynamics of acorn barnacle hummocking. Ecology 79:1382-1394.

Black, K. P., and P. J. Moran. 1991. Influence of hydrodynamics on the passive dispersal and initial recruitment of larvae of Acanthaster planci (Echinodermata: Asteroidea) on the Great Barrier Reef. Marine Ecology Progress Series 69:55-65.

Breitburg, D. L. 1992. Episodic hypoxia in Chesapeake Bay: interacting effects of recruitment, behavior, and physical disturbance. Ecological Monographs 62:525-546.

Breitburg, D. L., M. A. Palmer, and T. Loher. 1995. Larval distributions and the spatial patterns of settlement of an oyster reef fish: response to flow and structure. Marine Ecology Progress Series 125:45-60.

Brown, J. H. 1971. Species richness of boreal mammals living in montane islands of the Great Basin. American Naturalist 105:467-478.

Butman, C. A., M. Fréchette, W. R. Geyer, and V. R. Starczak. 1994. Flume experiments on food supply to the blue mussel Mytilus edulis L. as a function of boundary-layer flow. Limnology and Oceanography 39:1755-1768.

Butman, C. A., J. P. Grassle, and C. M. Webb. 1988. Substrate choices made by marine larvae settling in still water and in a flume flow. Nature 333:771-773.

Carriker, M. R., and P. M. Gaffney. 1996. A catalogue of selected species of living oysters (Ostreacea) of the world. Pages 1-18 in V. S. Kennedy, R. I. E. Newell, and A. F. Ebele, editors. The eastern oyster, Crassostrea virginica. Maryland Sea Grant, College Park, Maryland, USA.

Day, R. W., and G. P. Quinn. 1989. Comparison of treatments after analysis of variance in ecology. Ecological Monographs 59:433-463.

Dayton, P. K. 1971. Competition, disturbance, and community organization: the provision and subsequent utilization of space in a rocky intertidal community. Ecological Monographs 41:351-389.

Dayton, P. K., and J. S. Oliver. 1980. An evaluation of experimental analyses of population and community patterns in benthic marine environments. Pages 93-120 in K. R. Tenore and B. C. Coull, editors. Marine benthic dynamics.
University of South Carolina Press, Columbia, South Carolina, USA.

Diaz, R. J., and R. Rosenberg. 1995. Marine benthic hypoxia: a review of its ecological effects and the behavioral responses of benthic macrofauna. Oceanography and Marine Biology: An Annual Review 33:245-303.

Eckman, J. E. 1983. Hydrodynamic processes affecting benthic recruitment. Limnology and Oceanography 28:241257.

Eggleston, D. B. 1990. Foraging behavior of the blue crab, Callinectes sapidus, on juvenile Crassostrea virginica: effects of prey density and size. Bulletin of Marine Science 46:62-82.

Ford, S. E., and M. R. Tripp. 1996. Diseases and defense mechanisms. Pages 581-660 in V. S. Kennedy, R. I. E. Newell, and A. F. Ebele, editors. The eastern oyster, Crassostrea virginica. Maryland Sea Grant, College Park, Maryland, USA.

Frankenberg, D. 1995. Report of North Carolina Blue Ribbon Advisory Council on Oysters. North Carolina Department of Environmental Health and Natural Resources, Raleigh, North Carolina, USA.

Fréchette, M., D. Lefaivre, and C. A. Butman. 1993. Bivalve feeding and the benthic boundary layer. Pages 325-369 in R. F. Dame, editor. Bivalve filter feeders in estuarine and coastal ecosystem processes. NATO ASI Series G, Ecological sciences, Volume 33. Springer-Verlag, Berlin, Germany.

Galtsoff, P. S. 1964. The American oyster Crassostrea virginica (Gmelin). Fishery Bulletin 64.

Genin, A., P. K. Dayton, P. F. Lonsdale, and F. N. Spiess. 1986. Corals on seamounts: evidence of current accelerations over deep-sea topography. Nature 332:59-61.

Grant, J., C. T. Enright, and A. Griswold. 1990. Resuspension and growth of Ostrea edulis: a field experiment. Marine Biology 104:51-59.

Grizzel, R. E., R. Langdon, and W. H. Howell. 1992. Growth responses of suspension-feeding bivalve molluscs to changes in water flow: differences between siphonate and non-siphonate taxa. Journal of Experimental Marine Biology and Ecology 162:213-228.

Gross, F., and J. C. Smyth. 1946. The decline of oyster populations. Nature 157:540-542.

Hargis, W. J., and D. S. Haven. 1988. The imperiled oyster industry of Virginia: a critical analysis with recommendations for restoration. Special report number 290 in applied marine science and ocean engineering. Virginia Sea Grant Marine Advisory Services. Virginia Institute of Marine Science, Gloucester Point, Virginia, USA.

Huffaker, C. B. 1958. Experimental studies on predation: dispersion factors and predator-prey oscillations. Hilgardia 27:343-383.

Hutchinson, G. E. 1961. Paradox of the plankton. American Naturalist 95:137-145.

Irlandi, E. A., and C. H. Peterson. 1991. Modification of animal habitat by large plants: mechanisms by which seagrasses influence clam growth. Oecologia 87:307-318.

Jones, C. G., J. H. Lawton, and M. Shachak. 1994. Organisms as ecosystem engineers. Oikos 69:373-386.

Jordan, S., C. Stenger, M. Olson, R. Batiuk, and K. Mountford. 1992. Chesapeake Bay dissolved oxygen goal for restoration of living resources. United States Environmental Protection Agency, Chesapeake Bay Program, Annapolis, Maryland, USA.

Kelleher, G., and R. Kenchington. 1992. Guidelines for establishing marine protected areas. The World Conservation Union (IUCN), Gland, Switzerland.

Kinne, O. 1963. The effect of temperature and salinity on marine and brackish water animals. Oceanography and Marine Biology: An Annual Review 1:301-340. 
Konar, B., and C. Roberts. 1996. Large-scale landslide effects on two exposed rocky subtidal areas. Botanica Marina 39:517-524.

Leichter, J. J., and J. D. Witman. 1997. Water flow over subtidal rock walls: relation to distribution and growth rates of sessile suspension feeders in Gulf of Maine. Journal of Experimental Marine Biology and Ecology 209:293-307.

Lenihan, H. S., J. H. Grabowski, and G. W. Thayer. 1998. Recruitment to and utilization of oyster reef habitat by commercially valuable crabs and fishes: an experiment with economic analysis. National Research Council. Final report Number 1-97. National Marine Fisheries Service, Beaufort, North Carolina, USA.

Lenihan, H. S., F. Micheli, S. W. Shelton, and C. H. Peterson. In press. The influence of multiple environmental stressors on susceptibility to parasites: an experimental determination with oysters. Limnology and Oceanography.

Lenihan, H. S., and C. H. Peterson. 1998. How habitat degradation through fishery disturbance enhances impacts of bottom water hypoxia on oyster reefs. Ecological Applications 8:128-140.

Lenihan, H. S., C. H. Peterson, and J. M. Allen. 1996. Does flow speed also have a direct effect on growth of active suspension feeders: an experimental test on oysters, Crassostrea virginica (Gmelin). Limnology and Oceanography 41:1359-1366.

Leonard, G. H., J. M. Levine, P. R. Schmidt, and M. D. Bertness. 1998. Flow-driven variation in intertidal community structure in a Maine estuary. Ecology 79:13951491.

Loya, Y. 1976. Effects of water turbidity and sedimentation on the community structure of Puerto Rico corals. Bulletin of Marine Science 26:450-466.

MacArthur, R. H., and J. W. MacArthur. 1961. On bird species diversity. Ecology 42:594-599.

MacKenzie, C. L. 1983. To increase oyster production in the northeastern United States. Marine Fisheries Review 45 : $1-23$.

1996. Management of natural populations. Pages 707-721 in V. S. Kennedy, R. I. E. Newell, and A. F. Ebele, editors. The eastern oyster, Crassostrea virginica. Maryland Sea Grant, College Park, Maryland, USA.

Mallin, M. A., and H. W. Paerl. 1994. Planktonic trophic transfer in an estuary: seasonal, diel, and community structure effects. Ecology 75:2168-2184.

Manly, B. F. J. 1992. Multivariate statistical methods: a primer. Chapman and Hall, London, UK.

Mann, K. H., and J. R. M. Lazier. 1991. Dynamics of marine ecosystems: biological-physical interactions in the oceans. Blackwell, Boston, Massachusetts, USA.

McNinch, J. E. 1997. Sedimentary processes and formation of a barrier island cape. Dissertation. University of North Carolina at Chapel Hill, North Carolina, USA.

Micheli, F. 1997. Effects of predator foraging behavior on patterns of prey mortality in marine soft bottoms. Ecological Monographs 67:203-224.

Middleton, G. V., and J. B. Southard. 1984. Mechanics of sediment flow. Second edition. Society of Paleontologists and Mineralogists Short course Number 3, Providence, Rhode Island, USA.

Mullineaux, L. S., and E. D. Garland. 1993. Larval recruitment in response to manipulated field flows. Marine Biology 116:667-683.

Mullineaux, L. S., and S. W. Mills. 1997. A test of the larval retention hypothesis in seamount-generated flows. Deep Sea Research, Part 1, Oceanographic Research Papers 44: 745-770.

Murray, D. R., editor. 1986. Seed dispersal. Academic Press, North Ryde, Australia.

Muschenheim, D. K. 1987. The dynamics of near-bed seston flux and suspension-feeding benthos. Journal of Marine Research 45:473-496.

National Weather Service. 1996. Annual compilation of wind data for 1995. Cherry Point Marine Air Station, North Carolina, USA.

Newell, R. I. E. 1988. Ecological changes in Chesapeake Bay: are they the result of overharvesting the American oyster? Pages 536-546 in M. P. Lynch and E. C. Krome, editors. Understanding the estuary: advances in Chesapeake Bay research. Chesapeake Bay Research Consortium, Publication 129, Baltimore, Maryland, USA.

Newell, R. I. E., and C. J. Langdon. 1996. Mechanisms and physiology of larval and adult feeding. Pages 109-139 in V. S. Kennedy, R. I. E. Newell, and A. F. Ebele, editors. The eastern oyster, Crassostrea virginica. Maryland Sea Grant, College Park, Maryland, USA.

Nowell, A. R. M., and P. A. Jumars. 1984. Flow environments of aquatic benthos. Annual Review of Ecology and Systematics 15:303-328.

Okamura, B. 1984. The effects of ambient flow velocity, colony size, and upstream colonies on the feeding success of Bryozoa. I. Conopeum stolonifera Ryland, an arborescent species. Journal of Experimental Marine Biology and Ecology 83:179-193.

Ortega, S., and J. P. Sutherland. 1990. Recruitment and growth of the eastern oyster, Crassostrea virginica, in North Carolina, USA. Estuaries 15:158-170.

Paerl, H. W., M. M. Mallin, C. A. Donahue, M. Go, and B. L. Peierls. 1995. Nitrogen loading sources and eutrophication of the Neuse River, North Carolina: direct and indirect roles of atmospheric deposition. Water Resources Research Institute, Publication 291. The University of North Carolina at Chapel Hill, North Carolina, USA.

Patterson, M. R. 1980. Hydrodynamical adaptations in $A l$ cyonium siderium (Octocorallia). Pages 183-200 in D. J. Schneck, editor. Biofluid mechanics. Plenum Press, New York, New York, USA.

Pietrafessa, L. J., G. S. Janowitz, T.-Y. Chao, R. H. Weisberg, F. Askari, and E. Noble. 1986. The physical oceanography of Pamlico Sound. University of North Carolina Sea Grant Publication UNC-WP-86-5, Raleigh, North Carolina, USA.

Rankin, K. L., L. S. Mullineaux, and W. R. Geyer. 1994. Recruitment of gem clams (Gemma gemma) near a headland wake. Estuaries 17:655-667.

Rothschild, B. J., J. S. Ault, P. Goulletquer, and M. Héral. 1994. Decline of the Chesapeake Bay oyster population: a century of habitat destruction and overfishing. Marine Ecology Progress Series 111:29-39.

Sale, P. F. 1991. Habitat structure and recruitment in coral reef fishes. Pages 197-210 in S. S. Bell, E. D. McCoy, and H. R. Mushinsky, editors. Habitat structure: the physical arrangement of objects in space. Chapman and Hall, London, UK.

Sanford, E., D. Bermudez, M. D. Bertness, and S. D. Gaines. 1994. Flow, food supply, and acorn barnacle population dynamics. Marine Ecology Progress Series 104:49-62.

Seliger, H. H., J. A. Boggs, and W. H. Biggley. 1985. Catastrophic anoxia in the Chesapeake Bay in 1984. Science 228:70-73.

Shumway, S. 1996. Natural environmental factors. Pages 467-513 in V. S. Kennedy, R. I. E. Newell, and A. F. Ebele, editors. The eastern oyster, Crassostrea virginica. Maryland Sea Grant, College Park, Maryland, USA.

Skilleter, G. A., and C. H. Peterson. 1994. Control of foraging behavior of individuals within an ecosystem context: the clam Macoma balthica and interactions between competition and siphon cropping. Oecologia 100:268-278.

Tenore, K. R. 1972. Macrobenthos of the Pamlico River estuary, North Carolina. Ecological Monographs 42:51-69.

Thayer, G. W., editor. 1992. Restoring the nation's marine 
environment. Maryland Sea Grant, College Park, Maryland, USA.

Turner, E. J., R. K. Zimmerfaust, M. A. Palmer, M. Luckenbach, and N. D. Pentcheff. 1994. Settlement of oyster (Crassostrea virginica) larvae: effects of water flow and a water soluble chemical cue. Limnology and Oceanography 39:1579-1593.

Underwood, A. J., and E. J. Denley. 1984. Paradigms, explanations, and generalizations about models for the structure of intertidal communities on rocky shores. Pages 151180 in D. R. Strong, L. Abele, and D. Simberloff, editors. Ecological communities: conceptual issues and the evidence. Princeton University Press, Princeton, New Jersey, USA.

Vogel, S. 1981. Life in moving fluids: The physical biology of flow. Princeton University Press, Princeton, New Jersey, USA

Wells, H. W. 1961. The fauna of oyster reefs with special reference to the salinity factor. Ecological Monographs 31: 239-266.

Wells, J. T., and S. L. Kim. 1989. Sedimentation in the Albemarle-Pamlico lagoonal system: synthesis and hypothesis. Marine Geology 98:263-284.
White, M. E., and E. A. Wilson. 1996. Predators, pests, and competitors. Pages 559-580 in V. S. Kennedy, R. I. E. Newell, and A. F. Ebele, editors. The eastern oyster, Crassostrea virginica. Maryland Sea Grant, College Park, Maryland, USA.

Wildish, D. J., and D. D. Kristmanson. 1979. Tidal energy and sublittoral macrobenthic animals in estuaries. Journal of the Fisheries Research Board of Canada 36:1197-1206. Wildish, D. J., and A. M. Saulnier. 1993. Hydrodynamic control of filtration in Placopecten magellanicus. Journal of Experimental Marine Biology and Ecology 174:65-82.

Wishner, K., L. Levin, M. Gowing, and L. S. Mullineaux. 1990. Involvement of the oxygen minimum in benthic zonation on a deep seamount. Nature 346:57-59.

Witman, J. D., J. J. Leichter, S. J. Genovese, and D. A. Brooks. 1993. Pulsed phytoplankton supply to the rocky subtidal zone influence of internal waves. Proceedings of the National Academy of Sciences, USA 90:1686-1690.

Zimmerman, R., T. J. Minello, T. Baumer, and M. Castiglione. 1989. Oyster reef as habitat for estuarine macrofauna. NOAA Technical Memorandum NMFS-SEFC-249. National Oceanic and Atmospheric Administration, Washington, D.C., USA. 